\title{
On the Precipitation of Intermetallic Compounds in Selected Solid-Solution-Strengthened Ni-Base Alloys and Their Effects on Mechanical Properties
}

\author{
H. M. Tawancy ${ }^{1}$
}

Received: 11 March 2017/ Accepted: 12 April 2017/Published online: 24 April 2017

(C) Springer Science+Business Media New York and ASM International 2017

\begin{abstract}
We have investigated the susceptibility of selected solid-solution-strengthened Ni-base alloys of commercial grades to precipitating intermetallic compounds during aging at elevated temperatures and the corresponding effects on mechanical properties. Depending upon the exact chemical composition and aging temperature as well as the precipitate morphology, some alloys are found to be susceptible to precipitating detrimental intermetallics, particularly $\mathrm{Ni}_{3} \mathrm{Mo}, \mathrm{Ni}_{4} \mathrm{Mo}$, mu, sigma, $\delta \mathrm{Ni}_{3} \mathrm{Nb}$ and Laves phase. However, in some cases, it is found that certain intermetallics can produce a good combination of strength and ductility such as the $\mathrm{Ni}_{2}(\mathrm{Mo}, \mathrm{Cr})$ with $\mathrm{Pt}_{2} \mathrm{Mo}-$ type superlattice as well as the $\gamma^{\prime \prime}$ phase of $\mathrm{Ni}_{3} \mathrm{Nb}$ with $\mathrm{DO}_{22}$-type superlattice. Also, it is demonstrated that in some cases, small addition of an alloying element such as $\mathrm{Fe}$ to a given alloy can decelerate the kinetics of forming detrimental intermetallic compounds; however, a similar addition to another alloy can produce an opposite effect.
\end{abstract}

Keywords Ni-base alloys · intermetallic compounds · mechanical properties $\cdot$ microstructure $\cdot$ electron microscopy

H. M. Tawancy

tawancy@kfupm.edu.sa

1 Center for Engineering Research, Research Institute, King Fahd University of Petroleum and Minerals, P.O. Box 1639, Dhahran 31261, Saudi Arabia

\section{Introduction}

Solid-solution-strengthened Ni-base alloys have many important applications in various industries including the petrochemical, oil, chemical process and power generation. This is because of their distinctive combination of mechanical strength, environmental resistance and fabricability [1-3]. To achieve those properties, each alloy is a multi-component system with $\mathrm{Ni}$ as a host metal containing various concentrations of several alloying elements such as $\mathrm{Cr}, \mathrm{Fe}, \mathrm{Mo}$ and $\mathrm{W}$ in addition to minor concentrations of other elements particularly C, Mn and Si [1]. Some alloys may also contain trace amounts of reactive elements such as $\mathrm{Y}$ and La. During the final stages of processing into wrought produces (sheets, plates, etc.), the respective product is heat-treated to produce an aggregate equiaxed grains of Ni-rich solid solution with face-centered cubic (fcc) structure, which usually contains various densities of randomly dispersed carbide particles enriched in transition metals such as $\mathrm{Mo}, \mathrm{W}$ and $\mathrm{Nb}$ depending upon the exact chemical composition. An example derived from the (NiMo)-based Hastelloy alloy B-2 is shown in Fig. 1.

From a thermodynamic point of view, a structure such as that shown in Fig. 1 exists in a metastable condition. Given sufficient activation energy such as aging at high temperatures can result in significant changes in microstructure and corresponding properties. In particular, relatively high concentrations of transition metals can render the alloy prone to precipitating intermetallic compounds. Although some of those compounds, which are classified as topologically close-packed phases, have detrimental effects on mechanical strength [4-8], others can have beneficial effects [9-14]. On the other hand, designers are frequently required to make alloy selection for certain applications, which require operational lifetime 
of several years. Therefore, maintaining an acceptable level of mechanical strength after long-term aging at high temperatures becomes an important requirement.

To elucidate the response of solid-solution-strengthened Ni-base alloys to precipitation of intermetallic compounds and the corresponding effect on mechanical properties, the present investigation has been undertaken. Alloys of commercial grades with compositions based on the $\mathrm{Ni}-\mathrm{Cr}-$ $\mathrm{Fe}-\mathrm{Mo}, \mathrm{Ni}-\mathrm{Cr}-\mathrm{Cr}-\mathrm{Fe}-\mathrm{Mo}-\mathrm{Nb}$, Ni-Mo and $\mathrm{Ni}-\mathrm{Mo}-\mathrm{Cr}$ systems are included in the study. Emphasis has been placed on the long-term thermal stability characteristics.

\section{Experimental Procedure}

All alloys investigated were in the form of sheets about $3 \mathrm{~mm}$ in thickness and $55 \times 10 \times 10 \mathrm{~mm}$ plates. Their chemical compositions are listed in Table 1. Metallographic specimens $(2 \mathrm{~cm} \times 2 \mathrm{~cm})$ were machined from the as-received sheets for thermal aging experiments and microstructural characterization. The mechanical properties were determined from standard tensile tests and Charpy impact toughness tests.

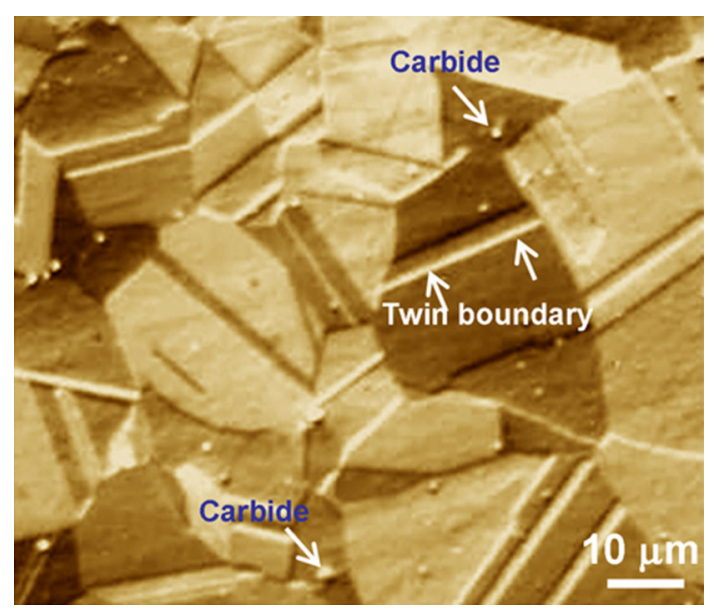

Fig. 1 Backscattered topographic SEM image illustrating the general microstructural features of a solid-solution-strengthened Ni-base alloy in the annealed condition (the example is derived from alloy B-2)
Thermal aging was carried out in box furnaces heated by electrical resistance for up to $16,000 \mathrm{~h}$ at temperatures ranging from 540 to $870{ }^{\circ} \mathrm{C}$. Oxide scale formed during aging was removed by sand blasting and mechanical abrasion. Detailed microstructural characterization was carried out using optical microscopy, scanning electron microscopy (SEM), and the transmission and scanning transmission electron microscopy (TEM/STEM) of an analytical electron microscope equipped with energydispersive spectrometer for microchemical analysis and operating at $200 \mathrm{keV}$. Specimens for optical microscopy were etched in a solution consisting of $80 \%$ concentrated $\mathrm{HCl}$ and $20 \%$ of 15 mol.\% chromic acid by volume. Thin foils for TEM/STEM experiments were prepared by the jet polishing technique in a solution consisting of $30 \%$ nitric acid in methanol by volume. All tensile tests were carried out at room temperature on sheet specimens with $50.8 \mathrm{~mm}$ gage length. The plate specimens used in Charpy impact tests had standard $\mathrm{V}$ notches about $2 \mathrm{~mm}$ in depth with $0.25 \mathrm{~mm}$ radius and $45^{\circ}$ angle.

\section{Experimental Results and Discussion}

\section{Alloy X}

Alloy $\mathrm{X}$ is based upon the $\mathrm{Ni}-\mathrm{Cr}-\mathrm{Fe}-\mathrm{Mo}$ system and has long been used as structural material in many gas turbine engine applications such as combustor cans, transition ducts, afterburners and tailpipes. Other applications include furnace and chemical process components. As an example, Fig. 2 shows the effect of $4000 \mathrm{~h}$ of exposure at 650,760 and $870{ }^{\circ} \mathrm{C}$ on the microstructure of alloy $\mathrm{X}$ as viewed on the scale of optical microscopy. For comparative purposes, the grain structure in the annealed condition is shown in Fig. $2 \mathrm{a}$ where a dispersion of $\mathrm{M}_{6} \mathrm{C}$-type carbide particles and annealing twins is observed as we have reported in an earlier study [3]. Massive precipitates with fine structure are observed in the matrix phase after $4000 \mathrm{~h}$ of aging at $650{ }^{\circ} \mathrm{C}$ as shown in Fig. $2 \mathrm{~b}$ in addition to continuous layers of precipitates at grain boundaries. Figure $2 \mathrm{c}$ shows that when the aging temperature is raised
Table 1 Chemical compositions of the alloys investigated (wt.\%)

\begin{tabular}{lllllrllllllll}
\hline Alloy & $\mathrm{Ni}$ & $\mathrm{Co}$ & $\mathrm{Cr}$ & $\mathrm{Fe}$ & $\mathrm{Mo}$ & $\mathrm{W}$ & $\mathrm{Nb}$ & $\mathrm{Ta}$ & $\mathrm{Ti}$ & $\mathrm{Mn}$ & $\mathrm{Si}$ & $\mathrm{C}$ & $\mathrm{S}$ \\
\hline $\mathrm{X}$ & Bal. & 1.71 & 21.09 & 18.82 & 8.75 & 0.25 & $\ldots$ & $\ldots$ & $\ldots$ & 0.65 & 0.45 & 0.09 & 0.005 \\
$\mathrm{~B}$ & Bal. & 0.61 & 0.70 & 5.66 & 26.57 & 0.23 & $\ldots$ & $\ldots$ & $\ldots$ & 0.33 & 0.32 & 0.02 & 0.002 \\
$\mathrm{~B}-2$ & Bal. & 0.10 & 0.12 & 0.38 & 26.62 & 0.26 & $\ldots$ & $\ldots$ & $\ldots$ & 0.21 & 0.28 & 0.002 & 0.002 \\
$\mathrm{~S}$ & Bal. & 0.23 & 15.14 & 0.44 & 14.23 & 0.25 & $\ldots$ & $\ldots$ & $\ldots$ & 0.53 & 0.31 & 0.004 & 0.005 \\
$\mathrm{C}-4$ & Bal. & 0.12 & 16.06 & 0.12 & 15.42 & 0.06 & $\ldots$ & $\ldots$ & $\ldots$ & 0.14 & 0.04 & 0.002 & 0.004 \\
$\mathrm{C}-276$ & Bal. & 1.85 & 15.01 & 5.65 & 16.19 & 3.33 & $\ldots$ & $\ldots$ & $\ldots$ & 0.43 & 0.04 & 0.002 & 0.006 \\
625 & Bal. & 0.21 & 20.57 & 3.49 & 9.05 & $\ldots$ & 3.63 & 0.02 & 0.22 & 0.57 & 0.49 & 0.05 & 0.004 \\
\hline
\end{tabular}


Fig. 2 Optical micrographs showing the effect of $8000 \mathrm{~h}$ of aging at different temperatures on the gross microstructure of alloy X. (a) Annealed condition. (b) $650{ }^{\circ} \mathrm{C}$. (c) $760{ }^{\circ} \mathrm{C}$. (d) $870{ }^{\circ} \mathrm{C}$

Fig. 3 Bright-field TEM images illustrating the microstructures of the precipitates formed in alloys $\mathrm{X}$ after aging at $650{ }^{\circ} \mathrm{C}$.

(a) $1000 \mathrm{~h}$ of aging; two types of precipitates are marked A (platelets) and B (discrete particles). (b) Highmagnification image of the platelets observed in (a) showing characteristic internal structure. (c) A blocky particle at a grain boundary with a similar internal structure observed in the same specimen. (d) Microstructure after $8000 \mathrm{~h}$ of aging
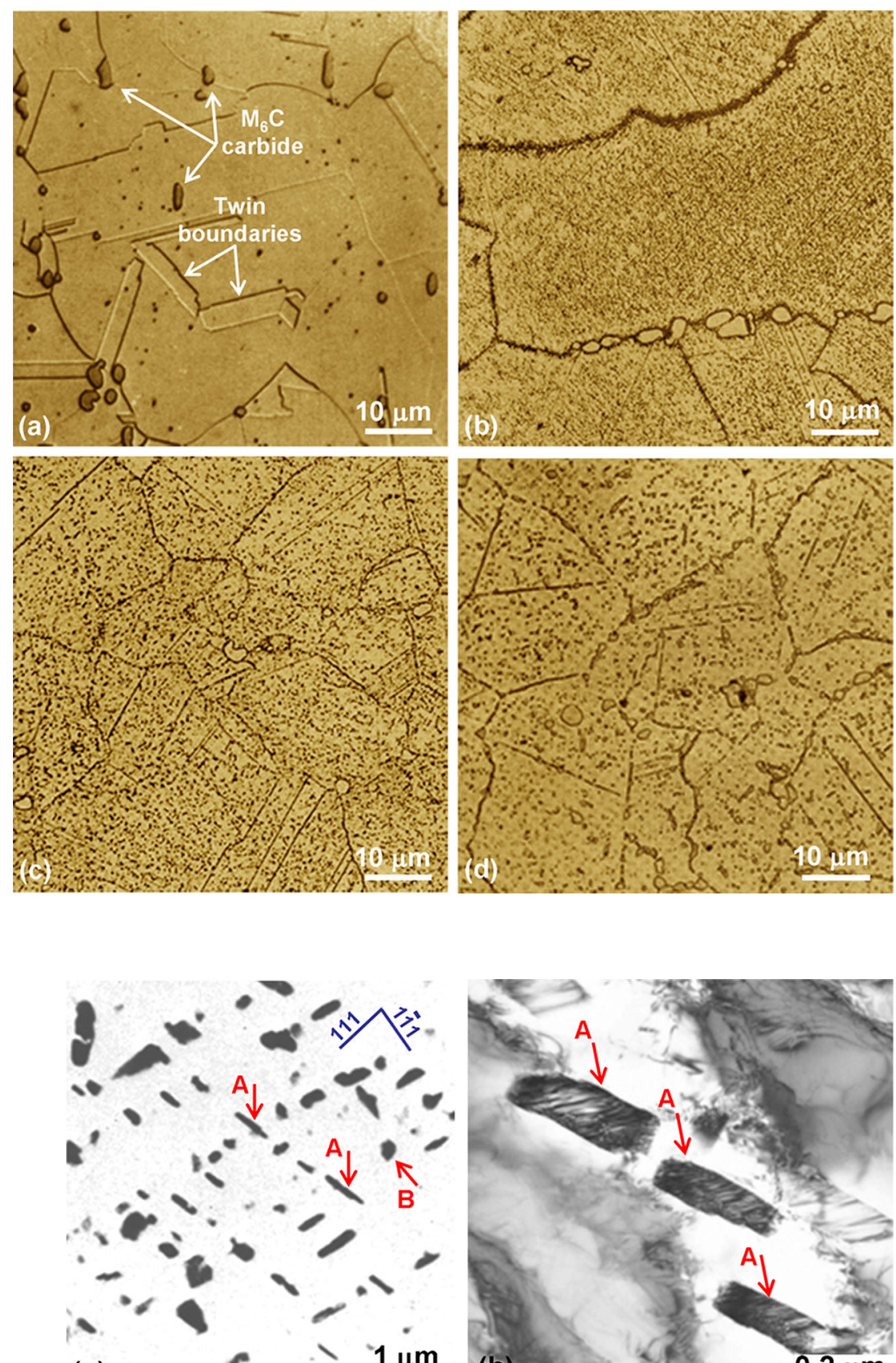

(a)
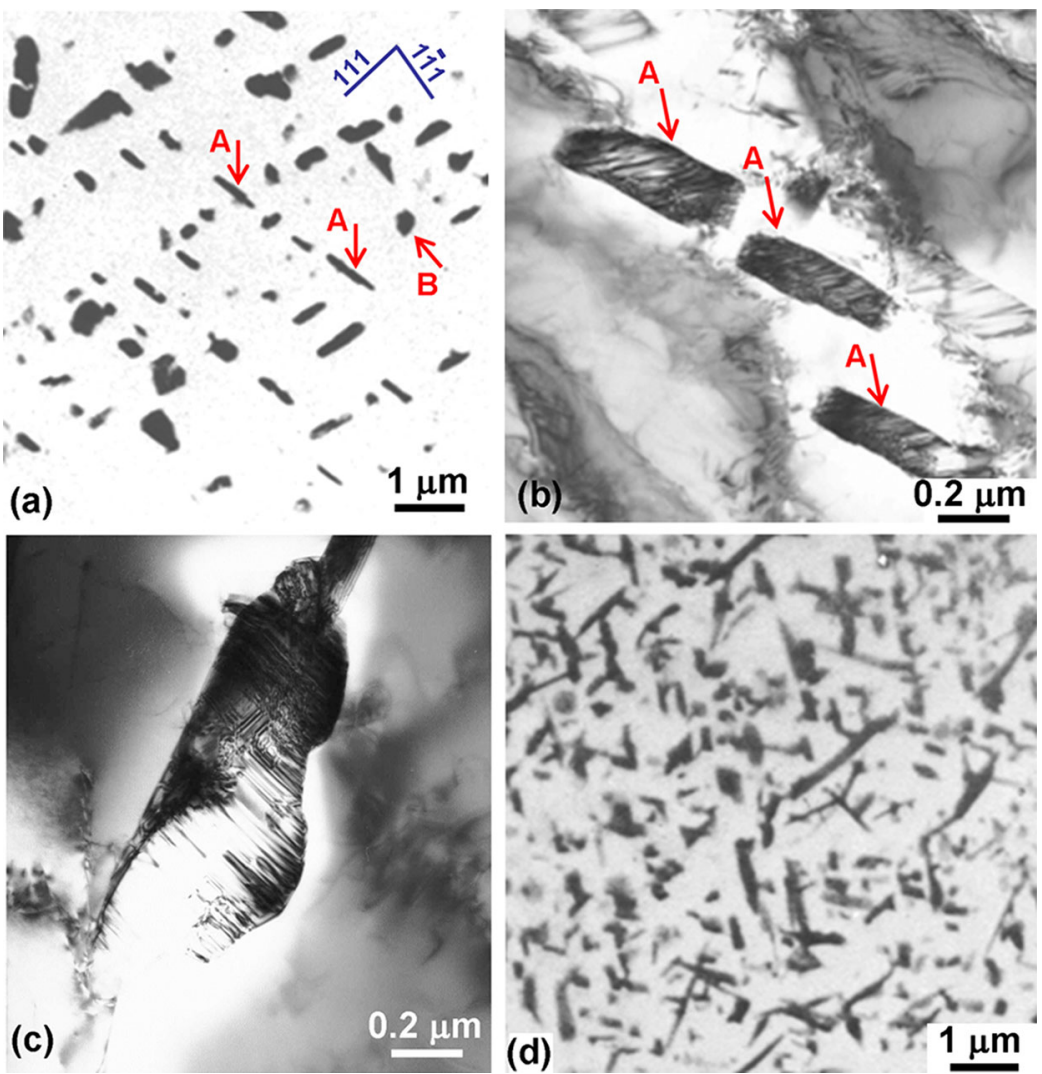

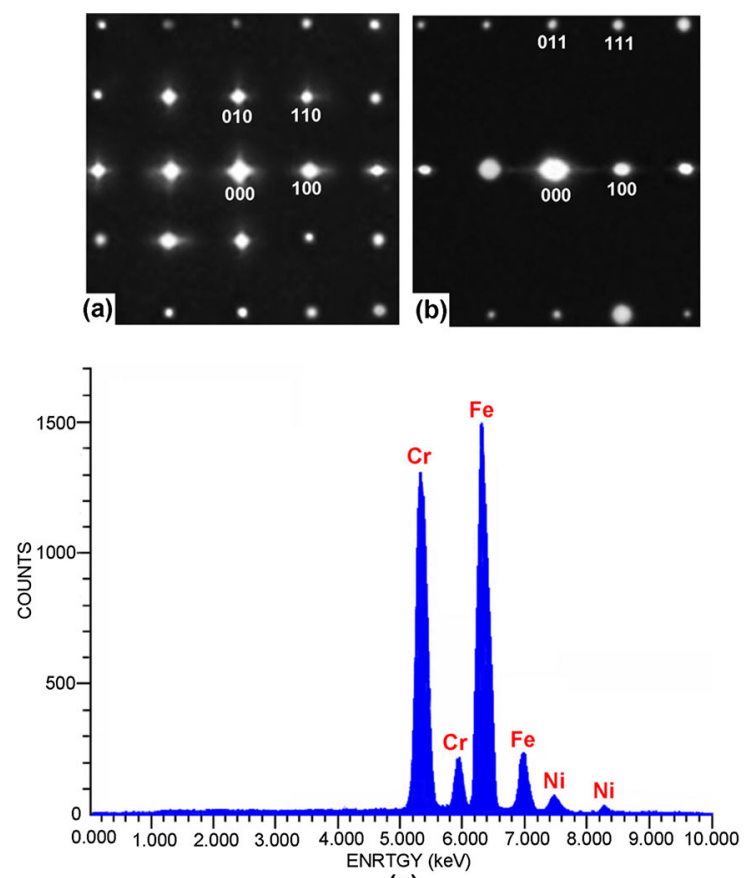

(c)

Fig. 4 Identification of $\mathrm{FeCr}$ sigma phase in the specimen of Fig. 3(a) and (b) are electron diffraction patterns derived from the precipitates with characteristic internal structures in Fig. $3 \mathrm{~b}$ and $\mathrm{c}$ and consistently indexed in terms of the tetragonal structure of sigma phase in [001] and [01ㅣ orientations, respectively. (c) Corresponding EDS spectrum showing the elemental composition of the sigma phase

to $760{ }^{\circ} \mathrm{C}$, the matrix precipitates become coarser and with less density as compared to aging at $650{ }^{\circ} \mathrm{C}$ (Fig. 2b) with comparatively thinner layers of grain boundary precipitates. Similarly, the matrix precipitates continue to become coarser and with less density after aging at $870{ }^{\circ} \mathrm{C}$ as observed in Fig. $2 \mathrm{~d}$. However, in this case, coarse discrete particles are observed at grain boundaries. Details about the nature of the precipitates observed in Fig. 2 as determined by TEM/STEM analysis are presented below.

Figure $3 \mathrm{a}$ is a bright-field STEM image showing the microstructure of the precipitates observed in the matrix phase after $1000 \mathrm{~h}$ of aging at $650{ }^{\circ} \mathrm{C}$. Two phases are distinguished: (1) aligned arrays of thin platelets with habits very close to $\{111\}_{\text {fcc }}$ planes such as those marked A and (2) discrete particles marked B. A bright-field TEM image of an aligned array of platelets with characteristic internal structure consisting of fine parallel striations as viewed at high magnification is shown in Fig. 3b. Blocky particles with similar internal structure are observed at grain boundaries as shown in the example of Fig. 3c. The density of the precipitates has continued to increase with exposure time as demonstrated in Fig. 3d showing the microstructure after $8000 \mathrm{~h}$ of exposure.

Both electron diffraction and microchemical analysis have shown that all precipitates with characteristic internal structure including those with platelet-type morphology in the matrix and blocky particles at grain boundaries are of the CrFe-type of sigma phase as illustrated in Fig. 4. The characteristic microdiffraction patterns shown in Fig. $4 \mathrm{a}$ and $\mathrm{b}$ are consistent with those of the tetragonal structure of CrFe sigma phase $(a \approx 0.9 \mathrm{~nm}, c \approx 0.5 \mathrm{~nm})$ in [001] and [011] orientations, respectively [15]. Also, it has been shown that platelets of sigma phase in the matrix with fcc structure maintain an orientation relationship of the type [15]:

$$
\begin{aligned}
& (001)_{\text {sigma }} \|(1 \overline{1} 1)_{\mathrm{fcc}} \\
& {[1 \overline{1} 0]_{\text {sigma }} \|[\overline{1} 12]_{\mathrm{fcc}}}
\end{aligned}
$$

which is consistent with the observation of Fig. 3a. Diffuse streaks of the diffraction spots along the [100] and [010] directions as observed in Fig. $4 \mathrm{a}$ and $\mathrm{b}$ are correlated with planar defects, particularly twins and stacking faults in the close-packed layer structure of sigma phase [8, 15]. The EDS spectrum of Fig. 4c shows the characteristic elemental composition of the sigma phase observed in Fig. 3 with $\mathrm{Fe}$ and $\mathrm{Cr}$ as the major elemental constituents. On the other hand, a discrete particle such as that marked $\mathrm{B}$ in Fig. $3 \mathrm{a}$ is identified as the Cr-rich $\mathrm{M}_{23} \mathrm{C}_{6}$ carbide [3]. It is noted here that primary carbides such as the $\mathrm{M}_{6} \mathrm{C}$ type shown in Fig. 2a tend to decompose during long-term thermal exposure at elevated temperatures providing a major source of $\mathrm{C}$, which leads to precipitation of the more stable $\mathrm{Cr}$-rich $\mathrm{M}_{23} \mathrm{C}_{6}$ carbide $[3,16]$. It is well known that the preferred nucleation sites of $\mathrm{M}_{23} \mathrm{C}_{6}$ carbide in austenitic-type alloys include dislocations, slip bands, incoherent sides of twin boundaries and grain boundaries [17-20].

Analysis of specimens aged for up to $16,000 \mathrm{~h}$ at 760 has shown that the $\mathrm{CrFe}$ sigma phase remains to be the only intermetallic compound present in the alloy; however, the respective structure becomes coarser with greater proportions of blocky particles in the matrix phase. However, after up to $16,000 \mathrm{~h}$ of aging at $870{ }^{\circ} \mathrm{C}$, there has been no evidence for the precipitation of sigma phase. Instead, a mu-type phase is found to be the only intermetallic compound precipitated in the alloy. In contrast to the sigma phase, the mu phase has assumed the morphology of blocky particles both in the matrix and at grain boundaries. Similar to the sigma phase, fine striations indicative of planar defects such as twins and stacking faults are observed within the mu phase particles as shown in the 
Fig. 5 Identification of mu phase in alloy $\mathrm{X}$ (specimen aged $8000 \mathrm{~h}$ at $870{ }^{\circ} \mathrm{C}$ ). (a) A brightfield TEM image showing a blocky particle with characteristic internal structure. (b) Corresponding electron diffraction pattern consistent with the hexagonal structure of mu phase in [001] orientations; the observed streaking of the diffraction spots along the [100] and [010] directions is due to planar defects on planes normal to the basal plane.

(c) Corresponding EDS spectrum showing the elemental composition of the mu phase
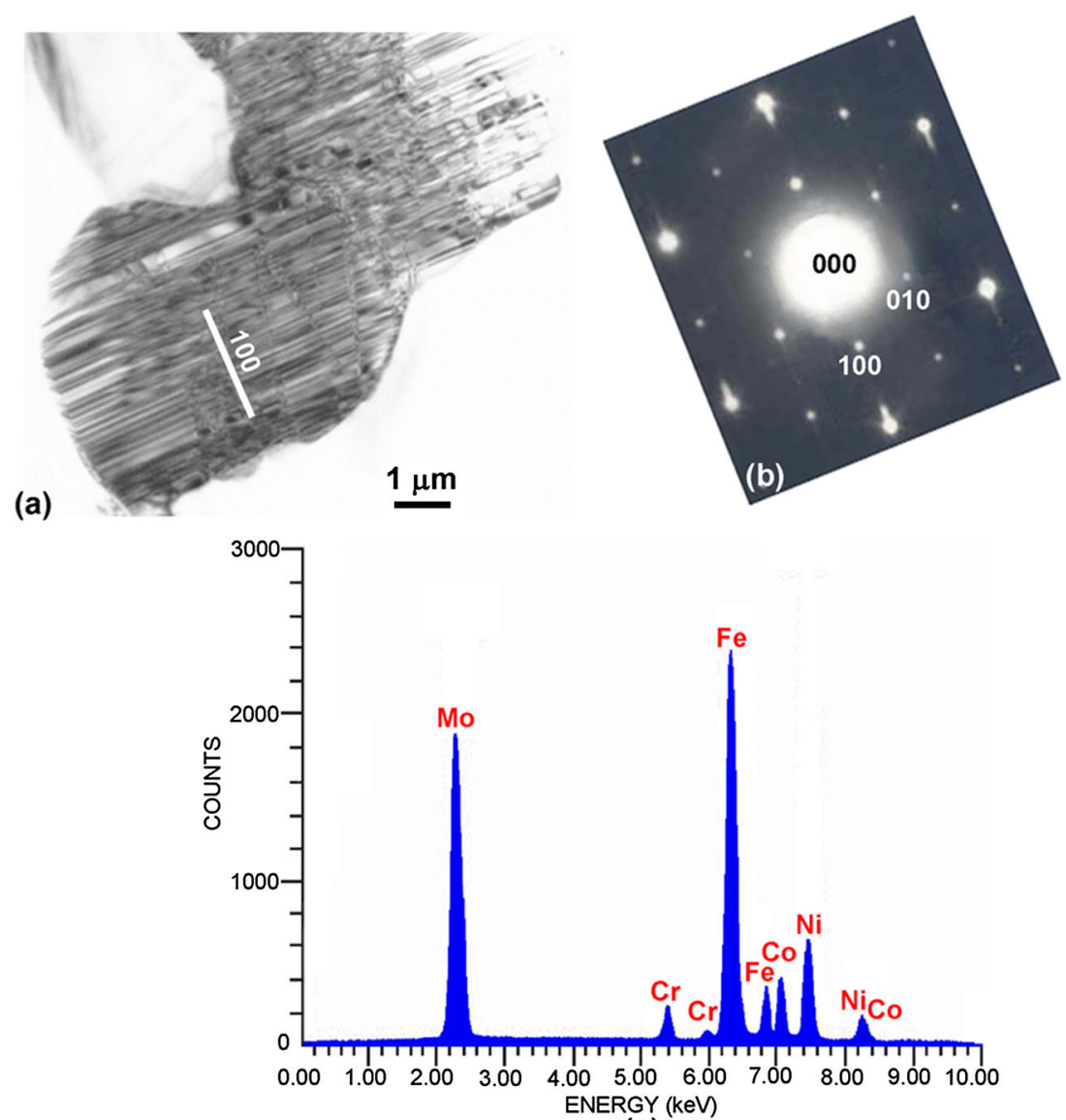

(c)

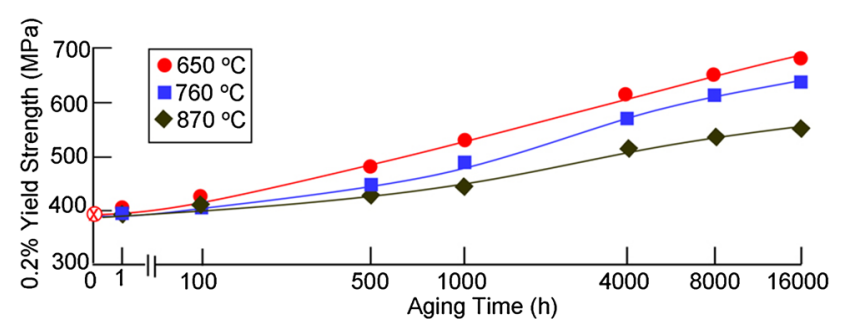

(a)

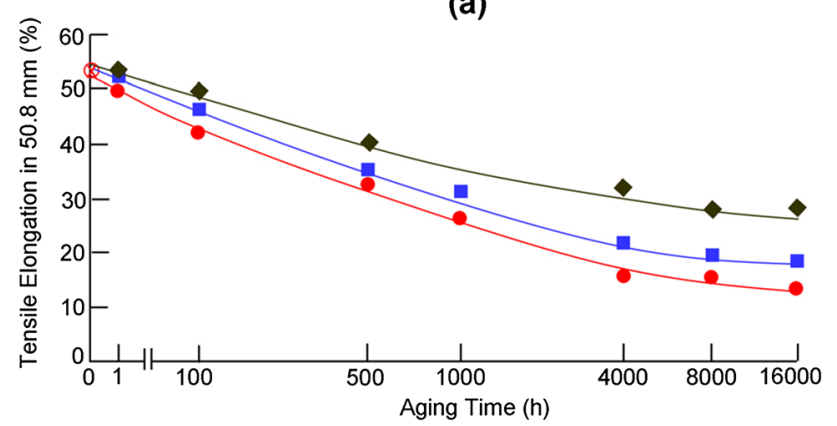

(b)

Fig. 6 Effect of up to $16,000 \mathrm{~h}$ of aging at different temperatures on the room temperature tensile properties of alloy $\mathrm{X}$. (a) $0.2 \%$ yield strength. (b) Tensile elongation in $50.8 \mathrm{~mm}$ gage length example of Fig. 5 for a specimen aged $8000 \mathrm{~h}$ at $870{ }^{\circ} \mathrm{C}$. Figure $5 \mathrm{a}$ is bright-field TEM image showing the internal structure of a mu phase particle. A corresponding electron diffraction pattern consistent with the hexagonal structure of mu phase isomorphous with $\mathrm{Fe}_{7} \mathrm{Mo}_{6}(a \approx 0.5 \mathrm{~nm}$, $c \approx 2.5 \mathrm{~nm}$ ) and in [001] orientation is shown in Fig. 5b. Streaking of the diffraction spots along the [100] and [010] directions indicates the presence of planar defects on planes normal to the basal plane [8, 21-23]. As shown in the corresponding EDS spectrum of Fig. 5c, Fe and Mo are the major elemental constituents indicative of a mu phase of the $\mathrm{Fe}_{7} \mathrm{Mo}_{6}$ type.

Topologically close-packed phases such as the sigma and mu phases are well known to degrade the mechanical strength with greater extent in the case of sigma phase, which is extremely hard and brittle $[8,16]$. The respective effect is reflected on the room temperature tensile properties shown in Fig. 6 as functions of aging time and temperature. It is observed from Fig. 6a that after $16,000 \mathrm{~h}$ of aging at 650 and $760{ }^{\circ} \mathrm{C}$, the $0.2 \%$ yield strength has increased from about $400 \mathrm{MPa}$ in the 
Fig. 7 Precipitation of $\mathrm{Ni}_{3} \mathrm{Mo}$ in alloy B after $1000 \mathrm{~h}$ of aging at $760{ }^{\circ} \mathrm{C}$. (a) Bright-field TEM image showing platelets of $\mathrm{Ni}_{3} \mathrm{Mo}$ in the fcc matrix phase. (b) Electron diffraction pattern in $[001]_{\mathrm{fcc}}$ orientation showing characteristic $\mathrm{DO}_{22}$ superlattice reflections of $\mathrm{Ni}_{3} \mathrm{Mo}$.

(c) Corresponding EDS spectrum showing the elemental composition of $\mathrm{Ni}_{3} \mathrm{Mo}$. (d) A schematic illustration of the atoms arrangement in the $\mathrm{DO}_{22}$ superlattice as viewed along the $[001]_{\mathrm{fcc}}$ direction; the ideal tetragonal superlattice unit cell is delineated by the dotted lines
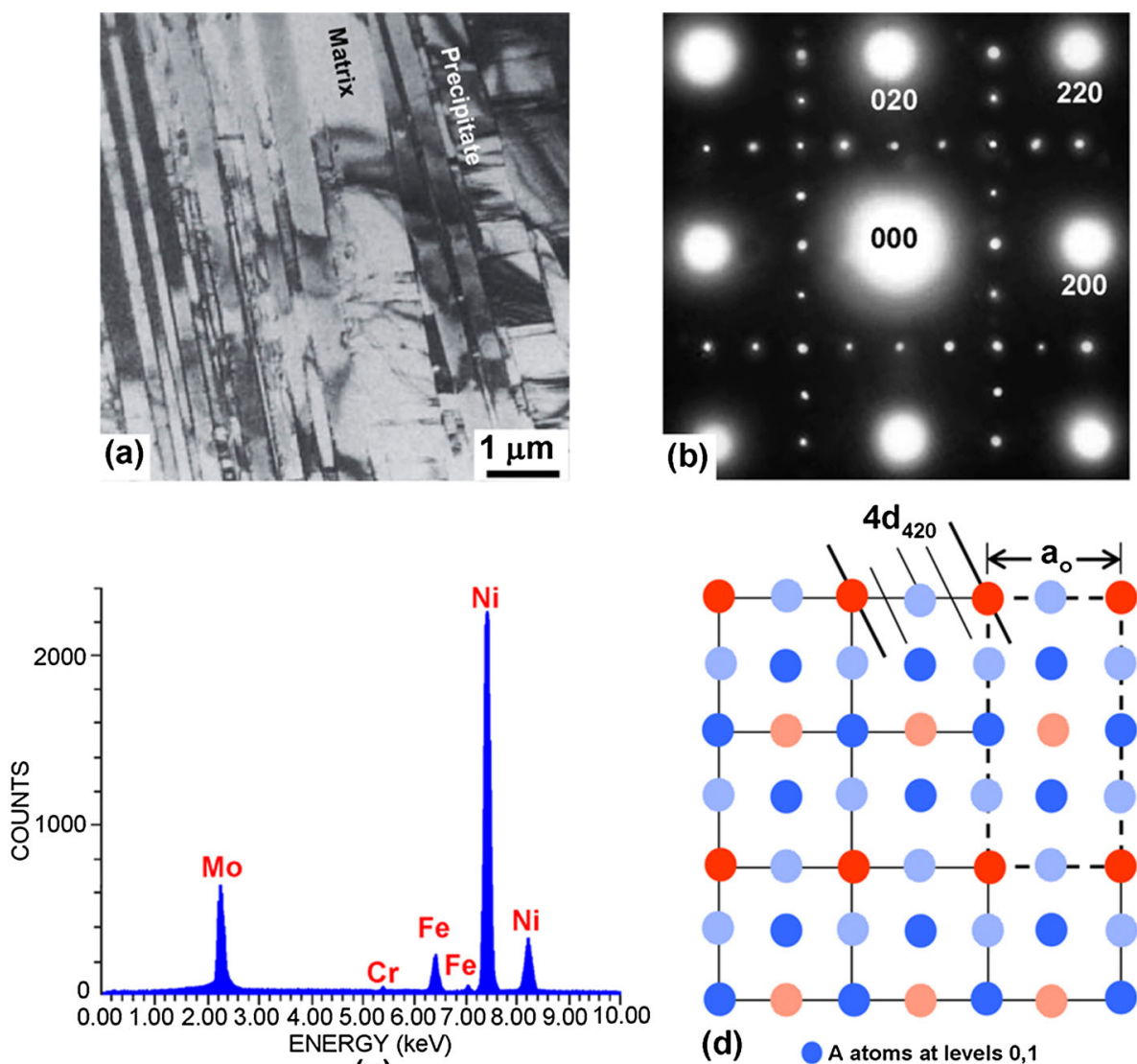

(c)

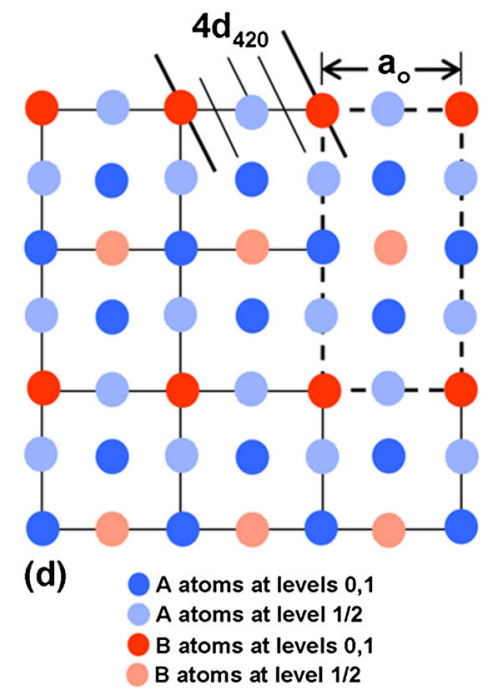

Table 2 Chemical compositions of the precipitate and matrix in Fig. 7 (wt.\%)

\begin{tabular}{llr}
\hline Element & Precipitate & Matrix \\
\hline $\mathrm{Ni}$ & 69.6 & 80.4 \\
$\mathrm{Mo}$ & 23.4 & 18.1 \\
$\mathrm{Fe}$ & 6.3 & 0.9 \\
$\mathrm{Cr}$ & 0.7 & 0.6 \\
\hline
\end{tabular}

annealed condition to about 670 and $610 \mathrm{MPa}$ with corresponding decrease in tensile ductility from $53 \%$ to about 12 and $20 \%$, respectively. However, these changes can only provide a qualitative assessment of the effect of intermetallic compounds due to the simultaneous precipitation of $\mathrm{M}_{23} \mathrm{C}_{6}$ carbide, which is expected to contribute to the changes in tensile properties observed in Fig. 6. On the other hand, the changes in tensile properties are observed to be less pronounced after aging at $870{ }^{\circ} \mathrm{C}$, which can be attributed at least partially to the absence of sigma phase. As can be seen, the $0.2 \%$ yield strength has increased from 400 to about $520 \mathrm{MPa}$ after $16,000 \mathrm{~h}$ of aging, while the tensile ductility has decreased from 53 to about $30 \%$.

\section{Alloys B and B-2}

Alloys of commercial grades based upon the Ni-Mo system include the Hastelloy alloys B and B-2, which are primarily developed for applications requiring high corrosion resistance particularly in reducing media. Both $\mathrm{Ni}_{4} \mathrm{Mo}$ with $\mathrm{D} 1_{a}$ superlattice and $\mathrm{Ni}_{3} \mathrm{Mo}$ based upon the $\mathrm{DO}_{22}$ superlattice are thermodynamically stable in the $\mathrm{Ni}-\mathrm{Mo}$ system; however, $\mathrm{Ni}_{2} \mathrm{Mo}$ with $\mathrm{Pt}_{2} \mathrm{Mo}$-type superlattice can form as an intermediate metastable phase during the precipitation of $\mathrm{Ni}_{4} \mathrm{Mo}$ and $\mathrm{Ni}_{3} \mathrm{Mo}[24,25]$.

The relatively higher $\mathrm{Fe}$ content of alloy $\mathrm{B}$ is found to enhance the precipitation of $\mathrm{Ni}_{3} \mathrm{Mo}$, which occurs with sluggish kinetics at temperatures in the range of $650-870{ }^{\circ} \mathrm{C}$. For example, Fig. 7 illustrates the microstructure of alloy B developed after $1000 \mathrm{~h}$ of aging at $760{ }^{\circ} \mathrm{C}$. Precipitates with long platelets extending across the grain are observed as shown in the bright-field TEM image of Fig. 7a. A corresponding electron diffraction pattern in $[001]_{\mathrm{fcc}}$ orientation is shown in Fig. $7 \mathrm{~b}$ where characteristic $\mathrm{DO}_{22}$ superlattice reflections are observed at all $1 / 4\langle 420\rangle_{\mathrm{fcc}}$ positions. The elemental composition of the precipitate is shown in the EDS spectrum of Fig. 7c. A 


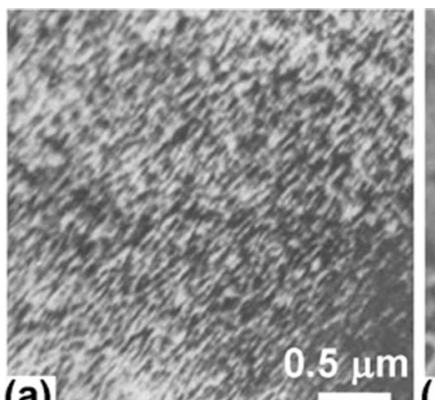

(a)
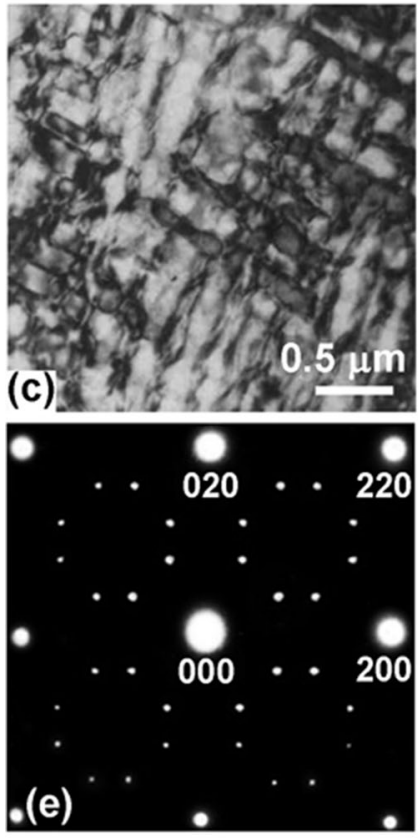
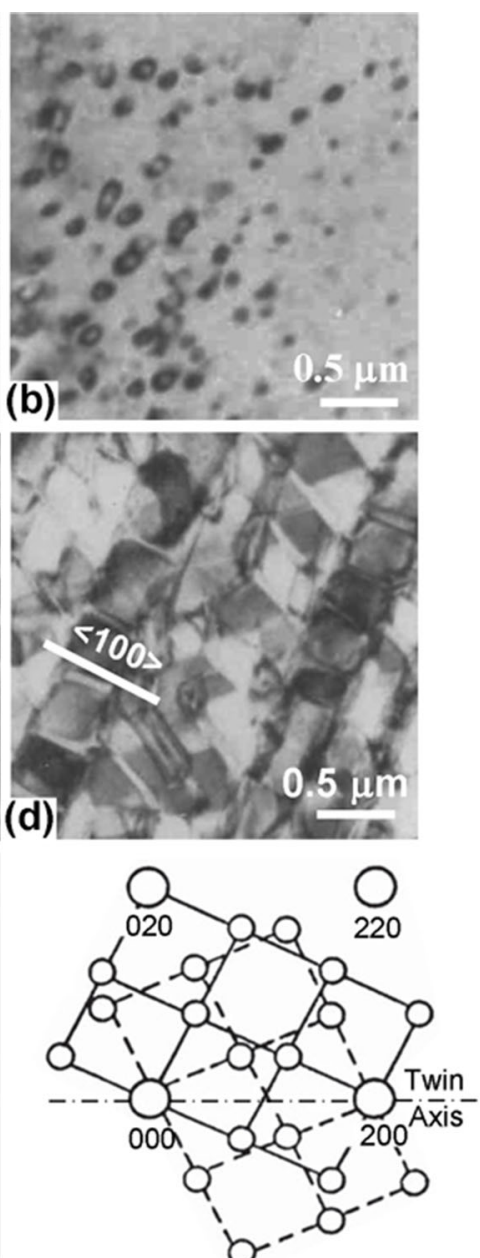

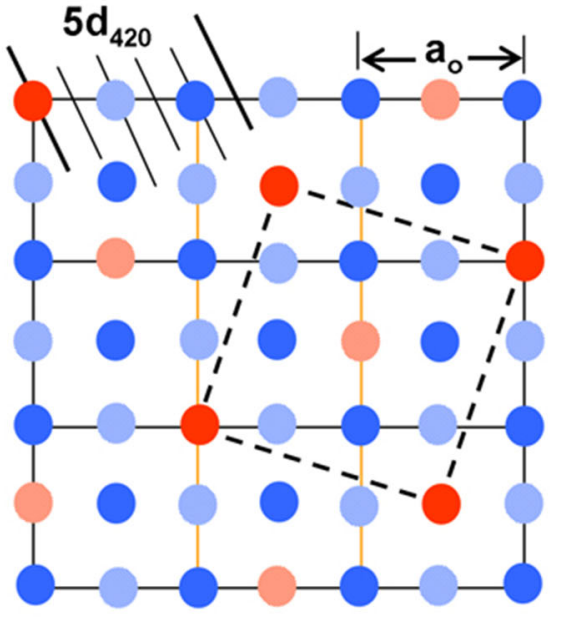

A atoms at levels 0,1

A atoms at level $1 / 2$

$B$ atoms at levels 0,1

$B$ atoms at level $1 / 2$

(g)
Fig. 8 Precipitation of $\mathrm{Ni}_{4} \mathrm{Mo}$ in alloy B-2 during aging at $760{ }^{\circ} \mathrm{C}$. (a), (b), (c) and (d) are bright-field TEM images showing the microstructures after $15 \mathrm{~min}, 24,100$ and $1000 \mathrm{~h}$ of aging, respectively. (e) $[001]_{\mathrm{fcc}}$ electron diffraction pattern corresponding to the image in (d) and showing characteristic $\mathrm{D} 1_{a}$ superlattice reflections at

schematic illustration of the crystallography of the $\mathrm{fcc} \rightarrow \mathrm{DO}_{22}$ superlattice transformation is shown in Fig. $7 d$ where every fourth $\{420\}_{\text {fcc }}$ plane becomes occupied with Mo atoms and in-between planes contain $\mathrm{Ni}$ atoms. However, it is noted here that the actual structure of $\mathrm{Ni}_{3} \mathrm{Mo}$ represents a slight orthorhombic distortion $(a=0.50 \mathrm{~nm}, b=0.42 \mathrm{~nm}, c=0.44 \mathrm{~nm})$ of the ideal tetragonal unit cell shown in Fig. 7d. Table 2 shows the chemical composition of $\mathrm{Ni}_{3} \mathrm{Mo}$ and the fcc matrix phase. It can be inferred from the relative $\mathrm{Fe}$ contents of the two phases that $\mathrm{Fe}$ is a stabilizer of $\mathrm{Ni}_{3} \mathrm{Mo}$. This is further confirmed by the behavior of alloy B-2, which is relatively free of $\mathrm{Fe}$ (Table 1) as demonstrated below.

Figure 8 summarizes the effect of aging time at $760{ }^{\circ} \mathrm{C}$ on the microstructure of alloy B-2. Aligned arrays of discrete particles of $\mathrm{Ni}_{4} \mathrm{Mo}$ are observed during the early stage of all $1 / 5\langle 420\rangle_{\mathrm{fcc}}$ positions. (f) Interpretation of the pattern in (e) as two twin-related patterns with $[100]_{\mathrm{fcc}}$ as twin axis. (g) A schematic illustration of the atoms arrangement in the $\mathrm{D} 1_{a}$ superlattice as viewed along the $[001]_{\text {fcc }}$ direction; the superlattice unit cell is delineated by the dotted lines

aging as shown in the bright-field TEM image of Fig. 8a $\left(15 \mathrm{~min}\right.$ at $\left.760{ }^{\circ} \mathrm{C}\right)$. The particles continue to grow with aging time, impinge upon each other and ultimately form as assembly of $\{100\}_{\mathrm{fcc}}$ transformation twins as illustrated in the bright-field TEM images of Fig. $8 \mathrm{~b}\left(24 \mathrm{~h}\right.$ at $\left.760{ }^{\circ} \mathrm{C}\right)$, c $\left(100 \mathrm{~h}\right.$ at $\left.760{ }^{\circ} \mathrm{C}\right)$ and $\mathrm{d}\left(1000 \mathrm{~h}\right.$ at $\left.760^{\circ} \mathrm{C}\right)$. Figure $8 \mathrm{e}$ shows an electron diffraction pattern in $[001]_{\mathrm{fcc}}$ orientation corresponding to the image of Fig. 8d and where characteristic D1 ${ }_{a}$ superlattice reflections of $\mathrm{Ni}_{4} \mathrm{Mo}$ (tetragonal; $a=b=0.57 \mathrm{~nm}, c=0.36 \mathrm{~nm})$ are observed at all $1 / 5$ $\langle 420\rangle_{\text {fcc }}$ positions. It is noted here that the diffraction pattern in Fig. 8e can be interpreted as two twin-related patterns with twin axis along $[001]_{\mathrm{fcc}}$ direction as schematically illustrated in Fig. 8f. The crystallography of the $\mathrm{fcc} \rightarrow \mathrm{D} 1_{a}$ superlattice transformation is schematically illustrated in Fig. 8g where every fifth $\{420\}_{\text {fcc }}$ plane becomes occupied with Mo atoms 


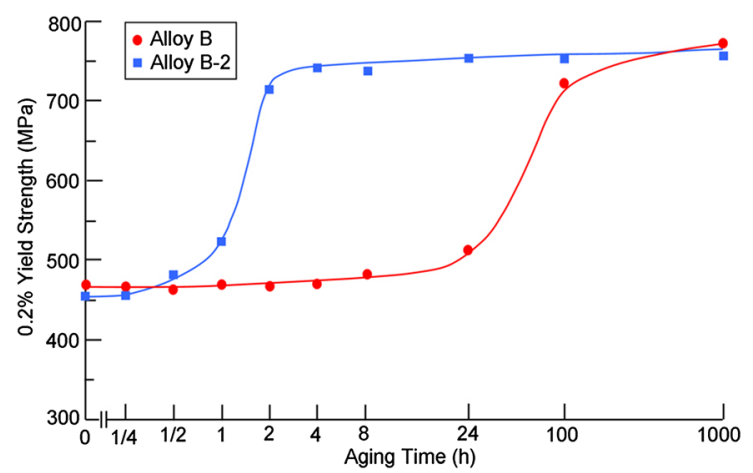

(a)

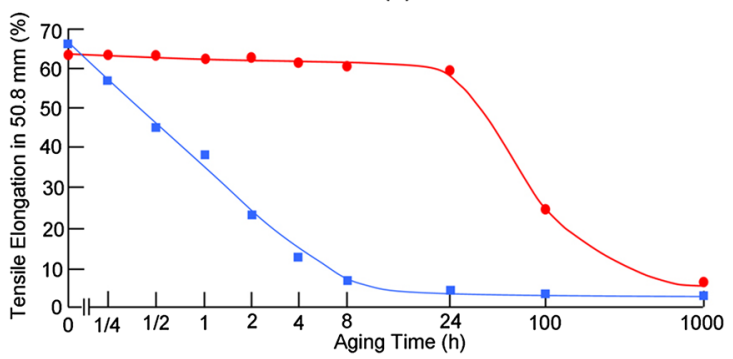

(b)

Fig. 9 Effect of up to $1000 \mathrm{~h}$ of aging at $760{ }^{\circ} \mathrm{C}$ on the room temperature tensile properties of alloys B and B-2. (a) $0.2 \%$ yield strength. (b) Tensile elongation in $50.8 \mathrm{~mm}$ gage length and planes in-between contain $\mathrm{Ni}$ atoms giving rise to the superlattice reflections observed in Fig. 8e.

The effect of aging time up to $1000 \mathrm{~h}$ at $760{ }^{\circ} \mathrm{C}$ on the room temperature tensile properties on alloys $\mathrm{B}$ and B-2 is illustrated in Fig. 9. Both alloys are shown to be significantly strengthened by precipitation of $\mathrm{Ni}_{3} \mathrm{Mo}$ and $\mathrm{Ni}_{4} \mathrm{Mo}$ (Fig. 9a) with considerable loss of tensile ductility (Fig. 9b). However, alloy $\mathrm{B}$ is distinguished by maintaining a relatively good combination of strength and ductility after up to $100 \mathrm{~h}$ of aging. This is in contrast to the case of alloy B-2 where considerable loss of ductility occurs after only $8 \mathrm{~h}$ of aging (Fig. 9b). Such difference in behavior can be correlated with the rapid kinetics of $\mathrm{Ni}_{4} \mathrm{Mo}$ precipitation in alloy B-2 as compared to the more sluggish kinetics of $\mathrm{Ni}_{3} \mathrm{Mo}$ precipitation in alloy $\mathrm{B}$, which can be correlated with its relatively high Fe content.

\section{Alloys S, C-4 and C-276}

Alloys S, C-4 and C-276 are essentially based upon the $\mathrm{Ni}-$ $\mathrm{Mo}-\mathrm{Cr}$ system and are distinguished by corrosion resistance in both reducing and oxidizing media. A common feature of the three alloys is found to be the precipitation of
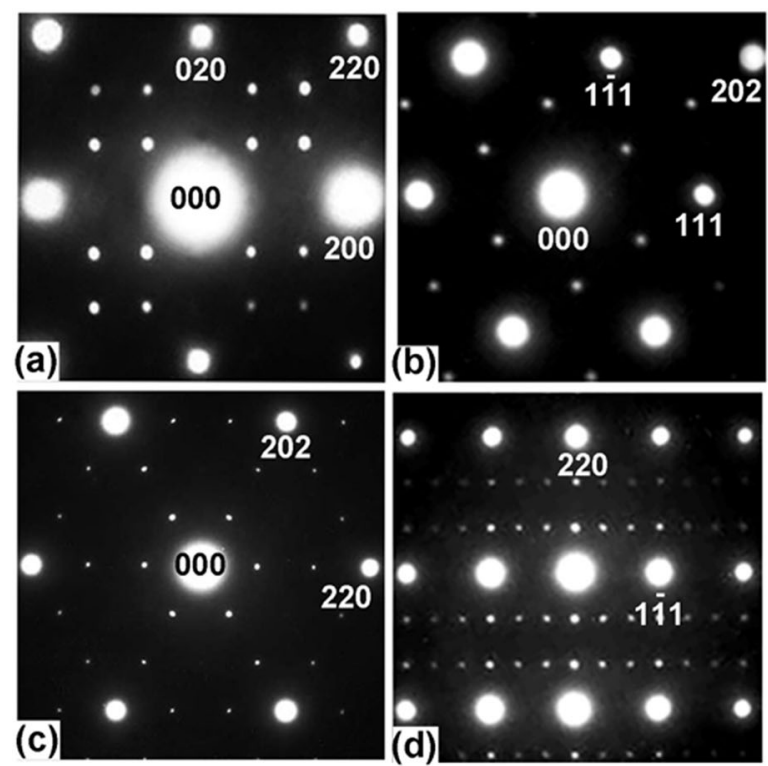

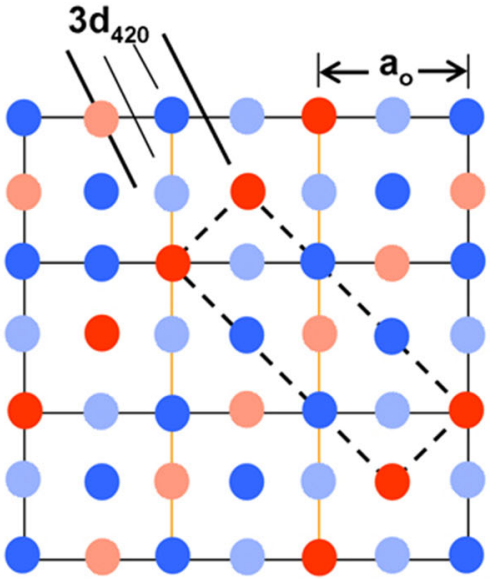

A atoms at levels 0,1

A atoms at level $1 / 2$

$B$ atoms at levels 0,1

$B$ atoms at level $1 / 2$

(e)
Fig. 10 Example illustrating the crystallography of the fcc $\rightarrow$ Pt2Mo-type superlattice of $\mathrm{Ni}_{2}(\mathrm{Mo}, \mathrm{Cr})$ in alloy $\mathrm{S}$ after $8000 \mathrm{~h}$ of aging at $540{ }^{\circ} \mathrm{C}$. (a), (b), (c) and (d) are electron diffraction patterns in $[001]_{\mathrm{fcc}},[110]_{\mathrm{fcc}},[111]_{\mathrm{fcc}}$ and $[112]_{\mathrm{fcc}}$ orientations, respectively, showing characteristic $\mathrm{Pt}_{2} \mathrm{Mo-type}$ superlattice reflections at all $1 / 3\langle 420\rangle_{\mathrm{fcc}}$ positions or equivalently at $1 / 3$ $\langle 220\rangle_{\text {fcc }}$ positions. (e) A schematic illustration of the atoms arrangement in the $\mathrm{Pt}_{2}$ Mo-type superlattice as viewed along the $[001]_{\mathrm{fcc}}$ direction; the superlattice unit cell is delineated by the dotted lines 
Fig. 11 Characteristic microstructure of the $\mathrm{Ni}_{2}(\mathrm{Mo}$, $\mathrm{Cr}$ ) intermetallic formed in alloys S, C-4 and C-276 after $8000 \mathrm{~h}$ of aging at $540{ }^{\circ} \mathrm{C}$.

(a) An example derived from alloys $\mathrm{S}$ to illustrate the microstructure as viewed in the bright-field imaging mode. (a), (b) and (c) are dark-field TEM images formed with $1 / 3\langle 420\rangle_{\text {fcc }}$ superlattice reflections and illustrating the microstructure of one variant of $\mathrm{Ni}_{2}(\mathrm{Mo}, \mathrm{Cr})$ intermetallic in alloys S, C-4 and C-276, respectively
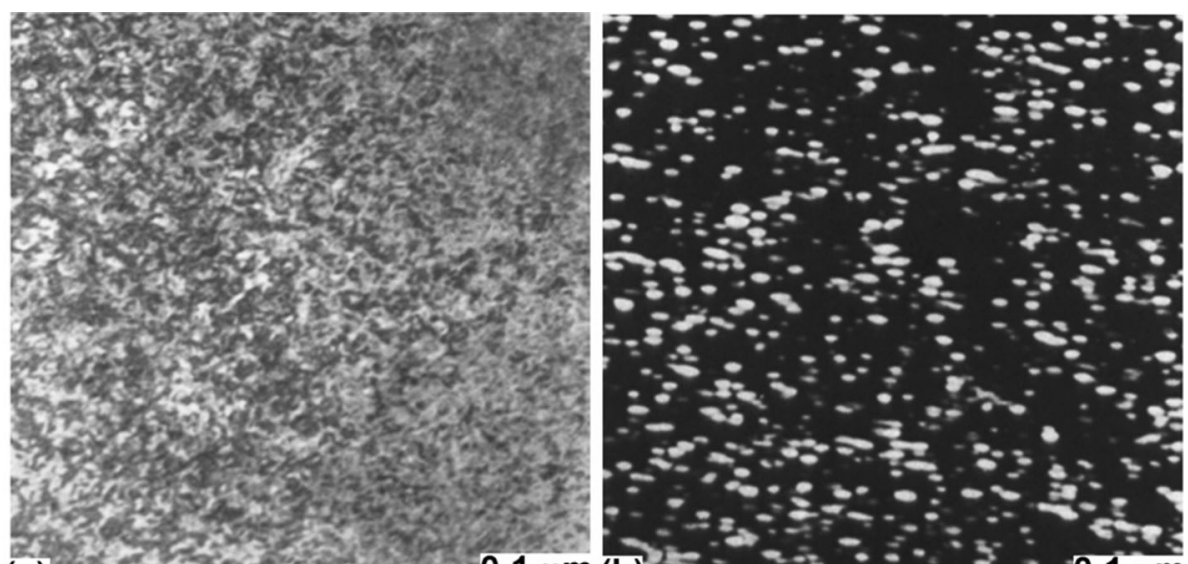

(a) $0.1 \mu \mathrm{m}$
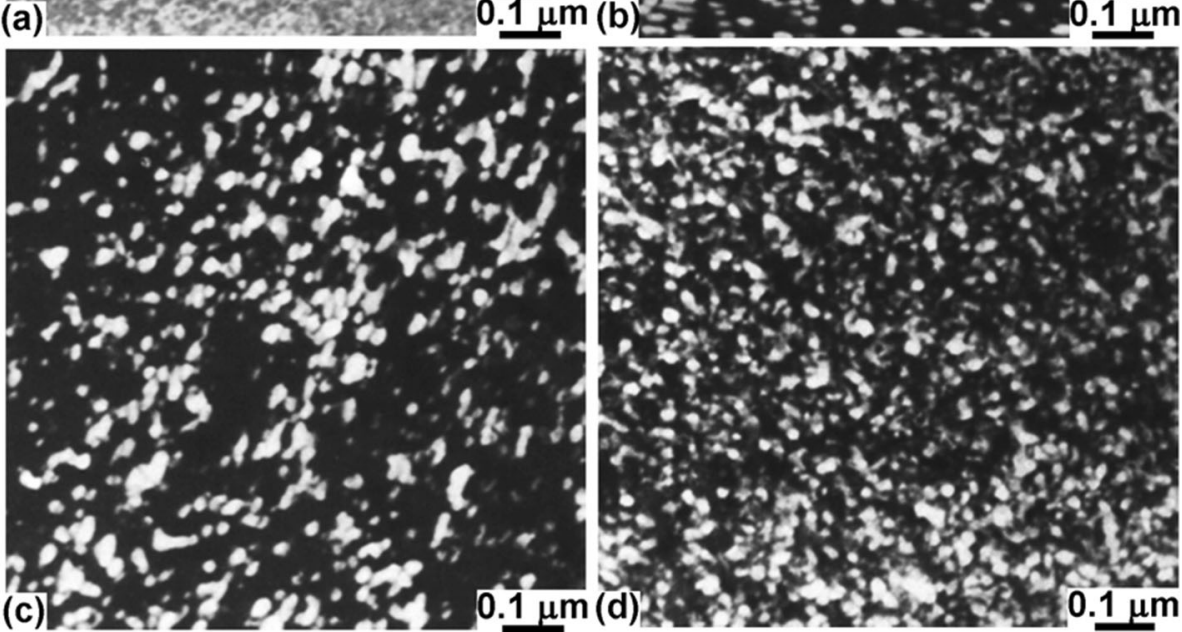

Cr-stabilized $\mathrm{Ni}_{2} \mathrm{Mo}$ with $\mathrm{Pt}_{2} \mathrm{Mo}$-type superlattice during aging at temperatures in the range of $540-760{ }^{\circ} \mathrm{C}$. This is demonstrated by the electron diffraction patterns shown in Fig. 10, which are derived from alloy $\mathrm{S}$ after $8000 \mathrm{~h}$ of aging at $540{ }^{\circ} \mathrm{C}$. The $[001]_{\mathrm{fcc}},[110]_{\mathrm{fcc}},[111]_{\mathrm{fcc}}$ and $[112]_{\mathrm{fcc}}$ diffraction patterns of Fig. 10a, b, c and d, respectively, are observed to contain characteristic reflections of $\mathrm{Pt}_{2} \mathrm{Mo}$-type superlattice at all $1 / 3\langle 420\rangle_{\text {fcc }}$ positions and equivalently at $1 / 3\langle 220\rangle_{\text {fcc }}$ positions. The characteristic positions of the superlattice reflections are correlated with the crystallography of the fcc $\rightarrow \mathrm{Pt}_{2} \mathrm{Mo}$-type superlattice transformation where every third $\{420\}_{\text {fcc }}$ plane becomes occupied with $\mathrm{Mo}$ and $\mathrm{Cr}$ atoms and planes in-between contain $\mathrm{Ni}$ atoms as schematically illustrated in Fig. 10e where the B atom can either be Mo or Cr. The same results are obtained for alloys C-4 and C-276. As an example, Fig. 11a shows a bright-field TEM image illustrating the microstructure of alloy $\mathrm{S}$ after $8000 \mathrm{~h}$ of aging at $540{ }^{\circ} \mathrm{C}$. The observed mottled contrast is typical of a large volume fraction of coherent second phase particles. Dark-field TEM images formed with $1 / 3\langle 420\rangle_{\mathrm{fcc}}$ reflections and illustrating the microstructure of one variant of the $\mathrm{Ni}_{2}(\mathrm{Mo}, \mathrm{Cr})$ phase in alloys S, C-4 and C-276 are shown in Fig. 11b, c and d, respectively. It is noted here that particles of the $\mathrm{Ni}_{2}(\mathrm{Mo}$, $\mathrm{Cr}$ ) intermetallic are distinguished by sizes on the nanoscale.

In contrast to aging at temperatures in the range of 650-760 ${ }^{\circ} \mathrm{C}$ where precipitation of $\mathrm{Ni}_{2}(\mathrm{Mo}, \mathrm{Cr})$ occurs, no intermetallic phases have been detected in alloys $\mathrm{S}$ and $\mathrm{C}-4$ after up to $16,000 \mathrm{~h}$ of aging at $870{ }^{\circ} \mathrm{C}$. However, alloy $\mathrm{C}-276$ is found to be highly susceptible to precipitation of mu phase even during the early stages of aging as shown in the example of Fig. 12. The mu phase is observed to assume a blocky particle morphology throughout the matrix and at grain boundaries similar to the case of alloy $\mathrm{X}$ described earlier when aged at $870{ }^{\circ} \mathrm{C}$ (Figs. 2c, 5). A particle of mu phase with the characteristic internal structure due to the presence of planar defects in the respective close-packed layer structure is shown in Fig. 12a. Figure 12b-e shows microdiffraction patterns derived from the particle in (a) at different orientations and consistently indexed in terms of the hexagonal structure of mu phase with $a=b=0.48 \mathrm{~nm}$ and $c=2.56 \mathrm{~nm}$. The corresponding EDS spectrum of Fig. 12f shows that $\mathrm{Ni}$ and Mo are the major elemental constituents of the particle in (a) with relatively high $\mathrm{Fe}$ concentration and smaller 
Fig. 12 Identification of mu phase in alloy C-276 after $1 \mathrm{~h}$ of aging at $870{ }^{\circ} \mathrm{C}$. (a) Bright-field TEM image illustrating a blocky particle of mu phase with characteristic internal structure. (b), (c-e) are corresponding microdiffraction patterns consistently indexed in terms of the hexagonal structure of mu

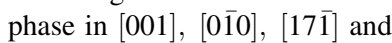

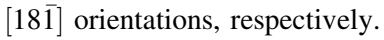
(f) Corresponding EDS spectrum showing the elemental composition of mu phase
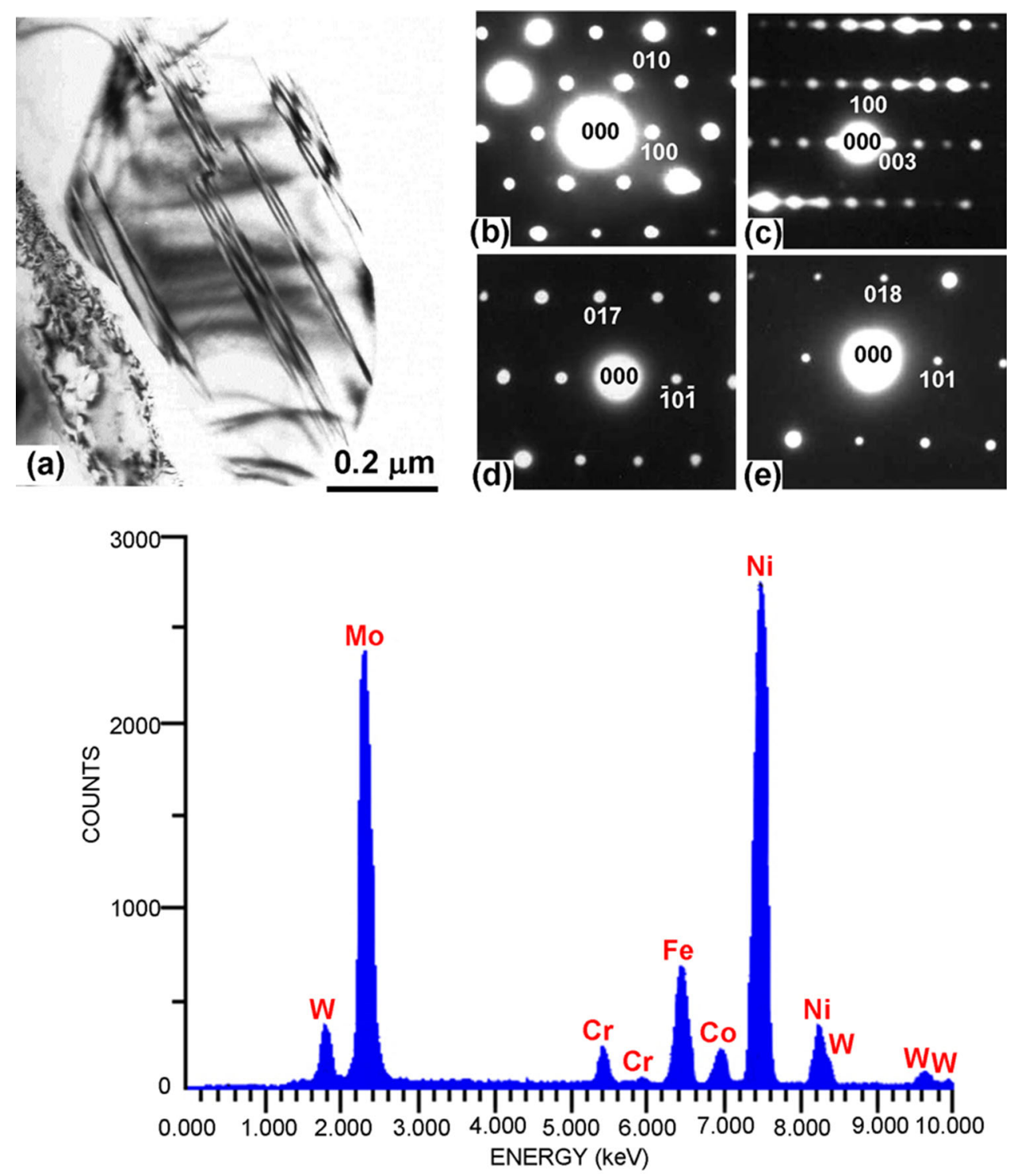

(f) concentrations of $\mathrm{W}$ and $\mathrm{Co}$ and $\mathrm{Cr}$. It is noted here that a mu phase with $\mathrm{Ni}_{7} \mathrm{Mo}_{6}$ is thermodynamically unstable in the Ni-Mo system unlike phases with $\mathrm{W}_{6} \mathrm{Co}_{7}, \mathrm{Mo}_{6} \mathrm{Co}_{7}$, $\mathrm{W}_{6} \mathrm{Fe}_{7}$ and $\mathrm{Mo}_{6} \mathrm{Fe}_{7}$ compositions which are thermodynamically stable [8]. On the other hand, it is well known that TCP phases with close-packed layer structures are electron compounds, which are stabilized over certain ranges of electron-to-atom ratios (e/a) [4, 8]. Therefore, the observation of Fig. 12 suggests that the combination of Fe and $\mathrm{Co}$ and $\mathrm{W}$ has contributed to stabilizing the mu phase in alloy C-276 and that the absence of mu phase in alloys S and C-4 can be correlated with their very small concentrations of $\mathrm{Fe}, \mathrm{Co}$ and $\mathrm{W}$ as shown in Table 1.

As an example, Fig. 13 illustrates the effect of up to $16,000 \mathrm{~h}$ of aging on the room temperature tensile properties of alloy S. The considerable strengthening observed after aging at $540{ }^{\circ} \mathrm{C}$ (Fig. 13a) while still maintaining a relatively high tensile ductility (Fig. 13b) is correlated with precipitation of the $\mathrm{Ni}_{2}(\mathrm{Mo}, \mathrm{Cr})$ phase with $\mathrm{Pt}_{2} \mathrm{Mo}$-type superlattice (Fig. 11b). However, aging at higher temperatures in the range of $650-870{ }^{\circ} \mathrm{C}$ is observed to have no significant effect on tensile properties. A quite similar behavior is observed in the case of alloy C-4. On the other hand, precipitation of mu phase in alloy C-276 particularly after aging at $870{ }^{\circ} \mathrm{C}$ is observed to have an adverse effect on mechanical strength as reflected by the results of Charpy impact tests shown in Fig. 14. The quite similar behavior of alloys S and C-4 is reflected by maintaining the same resistance to fracture toughness after up to $16,000 \mathrm{~h}$ of aging at $870{ }^{\circ} \mathrm{C}$. In contrast, the resistance to impact fracture toughness of alloy C-276 is considerably degraded with continued aging, which can be correlated with 


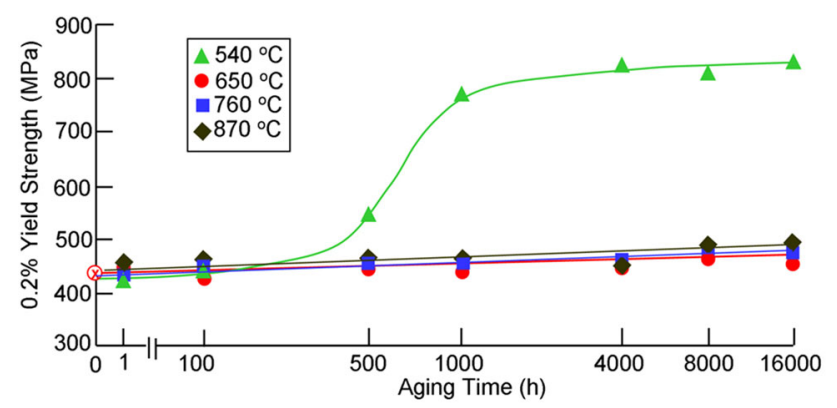

(a)

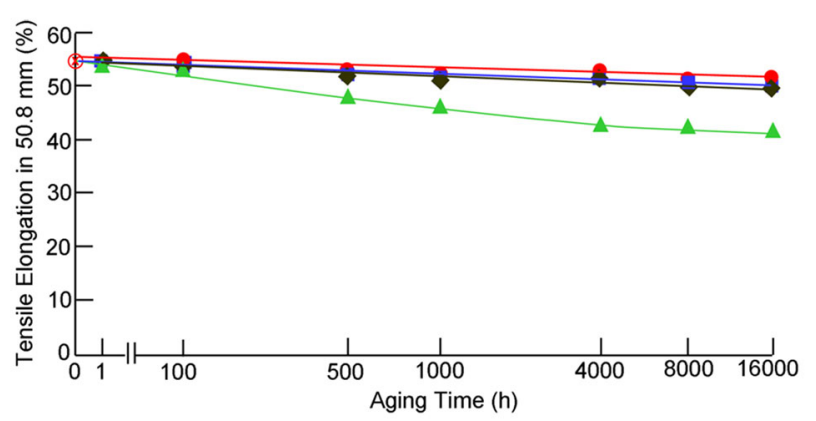

(b)

Fig. 13 Effect of up to $16,000 \mathrm{~h}$ of aging at different temperatures on the room temperature tensile properties of alloy S. (a) $0.2 \%$ yield strength. (b) Tensile elongation in $50.8 \mathrm{~mm}$ gage length

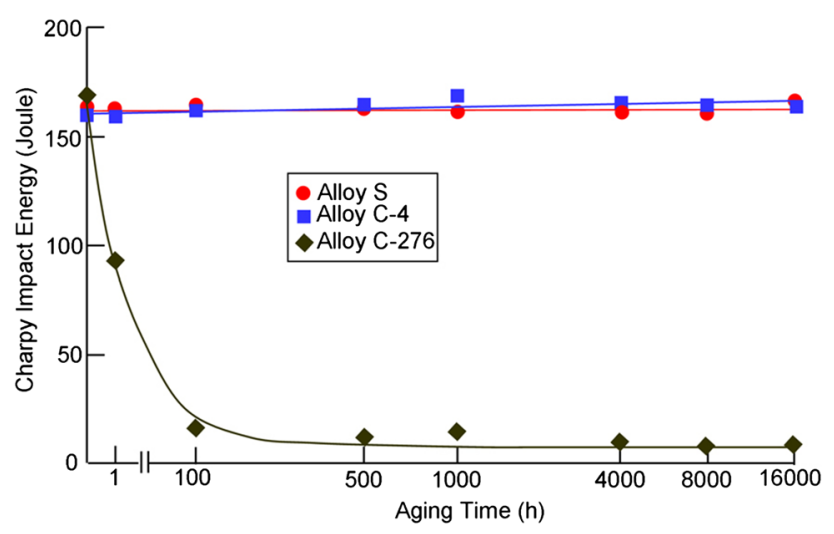

Fig. 14 Effect of up to $16,000 \mathrm{~h}$ of aging at $870{ }^{\circ} \mathrm{C}$ on the room temperature impact toughness of alloys S, C-4 and C-276

precipitation of mu phase. Evidently, the superior strength of alloys S and C-4 over alloy C-276 can be correlated with the balanced concentrations $\mathrm{W}, \mathrm{Fe}$ and $\mathrm{Co}$, which deters the precipitation of mu phase.

\section{Alloy 625}

Alloy 625 is distinguished by its widespread applications in the aerospace, power generation and chemical process industries [26]. Reference to Table 1 indicates that alloy 625 is essentially a $\mathrm{Ni}-\mathrm{Mo}-\mathrm{Cr}$, which differs from alloy
C-276 in that: (1) It has higher concentration of $\mathrm{Cr}$, (2) lower Mo content and higher Si content, and (3) W is replaced by $\mathrm{Nb}$. Such differences are found to deter the formation of mu phase as well as the $\mathrm{Ni}_{2}(\mathrm{Mo}, \mathrm{Cr})$ intermetallic found in alloy C-276. However, the presence of $\mathrm{Nb}$ is found to stabilize the polymorphic versions of $\mathrm{Ni}_{3} \mathrm{Nb}$ $\left(\gamma^{\prime \prime}\right.$ and $\delta$ phases) during aging at temperatures in the range $650-870{ }^{\circ} \mathrm{C}$. Also, the higher $\mathrm{Si}$ content is found to stabilize Ni-Mo Laves phase as demonstrated below.

Figure 15 shows the functional dependence of microstructure on aging time at $760{ }^{\circ} \mathrm{C}$ as viewed on the scale of optical microscopy. Precipitate particles observed in the annealed condition (Fig. 15a) are found to be a mixture of primary carbides of the Mo-rich $\mathrm{M}_{6} \mathrm{C}$ type and $\mathrm{Nb}$-rich MC type [3]. After $24 \mathrm{~h}$ of aging, secondary precipitates are observed at grain boundaries as shown in Fig. 15b. The grain boundary precipitates become more massive after $100 \mathrm{~h}$ of aging in addition to the presence of fine precipitates within the grains, which assume the morphology of short platelets (Fig. 15c). With continued aging, the platelets increase in density and length as shown in Fig. 15d (500 h) and e (1000 h). The results of analyzing the microstructure of the precipitates observed in Fig. 15 on the finer scale of TEM/STEM are summarized in the examples given below.

During the early stages of aging at $650{ }^{\circ} \mathrm{C}$, very thin precipitates on the nanoscale are observed as shown in the bright-field TEM image of Fig. 16a corresponding to $8 \mathrm{~h}$ of aging. The inset is a corresponding electron diffraction pattern in [001] orientation of the fcc matrix phase. Streaking of the diffraction spots along the $[200]_{f c c}$ and $[020]_{\text {fcc }}$ directions indicates that the very thin precipitates have nucleated on the cubic planes. The corresponding lattice image of $(200)_{\text {fcc }}$ planes in Fig. 16b shows that the precipitate thickness is about $1.5 \mathrm{~nm}$. It is noted here that the microstructural features observed in Fig. 16a resemble the GB zones observed in the well-known $\mathrm{Al}-4 \mathrm{wt} . \% \mathrm{Cu}$ alloy [27].

The thin precipitates observed in Fig. 16 are subsequently replaced by aligned arrays of discrete particles on the nanoscale during the later stages of aging at $650{ }^{\circ} \mathrm{C}$ as demonstrated in Fig. 17. A bright-field TEM image illustrating the morphology of the particles after $1000 \mathrm{~h}$ of aging is shown in Fig. 17a. At this stage, the streaking of the fcc matrix reflections observed in Fig. 16a is replaced by the characteristic reflections of the $\mathrm{DO}_{22}$ superlattice at all $1 / 4\langle 420\rangle_{\text {fcc }}$ positions as shown in the $[001]_{\text {fcc }}$ diffraction pattern of Fig. 17b, which resembles the case described earlier for $\mathrm{Ni}_{3} \mathrm{Mo}$ in alloy B (Fig. 7). Figure 17c shows a dark-field TEM image formed with the encircled superlattice reflection in (b) and illustrating the morphology of one variant of aligned arrays $\gamma^{\prime \prime}$ particles with nanoscale size. The corresponding elemental composition is shown in 


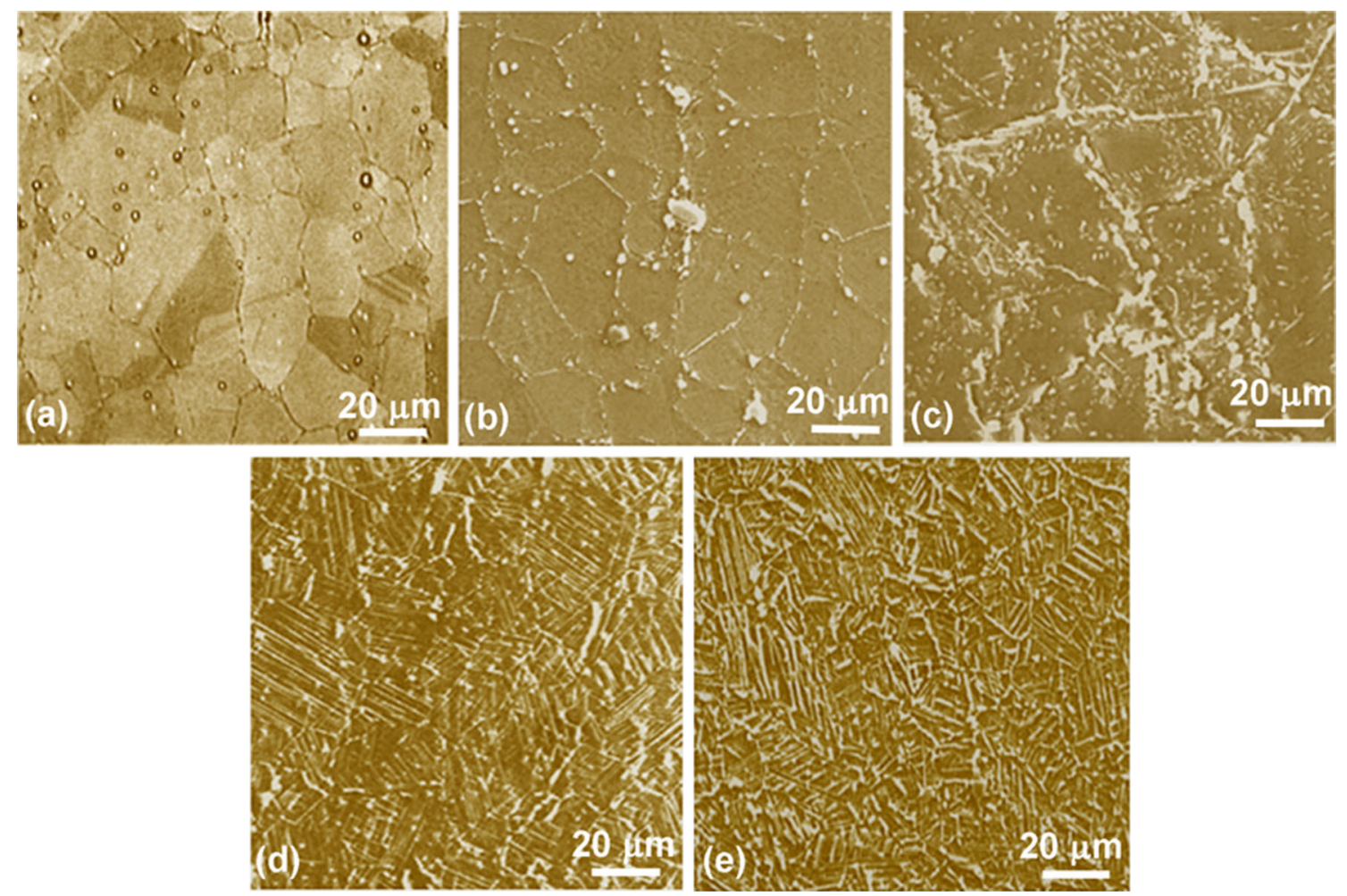

Fig. 15 Optical micrographs illustrating the effect of aging time at $760{ }^{\circ} \mathrm{C}$ on the microstructure of alloy 625 . (a) Annealed condition. (b) $24 \mathrm{~h}$. (c) 100 h. (d) 500 h. (e) $1000 \mathrm{~h}$

Fig. 16 Effect of $8 \mathrm{~h}$ of aging at $650{ }^{\circ} \mathrm{C}$ on the microstructure of alloy 625. (a) Bright-field TEM image showing very thin precipitates; the inset is an electron diffraction pattern in $[001]_{\mathrm{fcc}}$ directions showing streaks along the $[200]_{\mathrm{fcc}}$ and $[020]_{\text {fcc }}$ directions. (b) Onedimensional lattice image of (200) fcc $_{\text {fc }}$ planes showing a coherent thin precipitate with a thickness of about $1.5 \mathrm{~nm}$
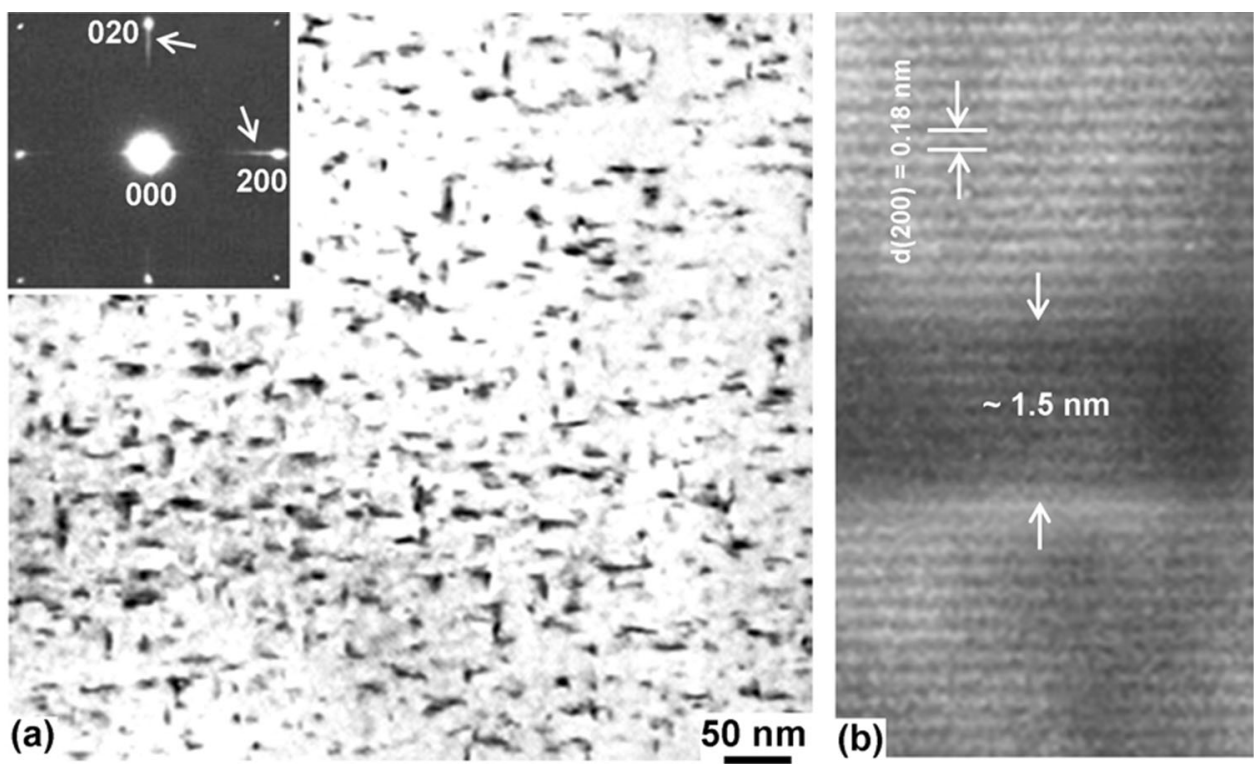

the EDS spectrum of Fig. 17d, which is consistent with $\mathrm{Ni}_{3} \mathrm{Nb}$-based composition.

Polymorphic $\gamma^{\prime \prime}$ phase $\rightarrow \delta$ phase transformation with $\mathrm{Ni}_{3} \mathrm{Nb}$-based composition is observed to eventually occur with continued aging at 650 and $760{ }^{\circ} \mathrm{C}$, where the $g^{\prime \prime}$ phase remains to be thermodynamically stable. An example is given in Fig. 18 for a specimen aged $4000 \mathrm{~h}$ at $760{ }^{\circ} \mathrm{C}$.
The $\delta$ phase assumes a platelet-type morphology as shown in the secondary electron SEM image of Fig. 18a. Figure $18 \mathrm{~b}$ is a bright-field TEM image showing platelets of the $\delta$ phase. A microdiffraction pattern consistent with the orthorhombic structure of $\delta$ phase in [001] orientation $(a=0.51 \mathrm{~nm}, b=0.43 \mathrm{~nm}, c=0.46 \mathrm{~nm})$ is shown in Fig. 18c. A corresponding dark-field TEM image formed 
Fig. 17 Microstructure of $\gamma^{\prime \prime}$ $\mathrm{Ni}_{3} \mathrm{Nb}$ formed in alloy 625 after $1000 \mathrm{~h}$ of aging at $650{ }^{\circ} \mathrm{C}$ (1000 $\mathrm{h}$ at 650 ). (a) Bright-field TEM image of the $\gamma^{\prime \prime}$ precipitates. (b) Corresponding electron diffraction pattern in $[001]_{\text {fcc }}$ orientation and showing characteristic reflections of the $\mathrm{DO}_{22}$ superlattice of $\gamma^{\prime \prime}$ phase at all $1 / 4\langle 420\rangle_{\text {fcc }}$ positions. (c) Dark-field TEM image formed with the encircled $1 / 4$ $\langle 420\rangle_{\text {fcc }}$ reflection in (b) and illustrating nanoscale size of one variant of $\gamma^{\prime \prime}$ particles.

(d) EDS spectrum illustrating the elemental composition of the $\gamma^{\prime \prime}$ phase
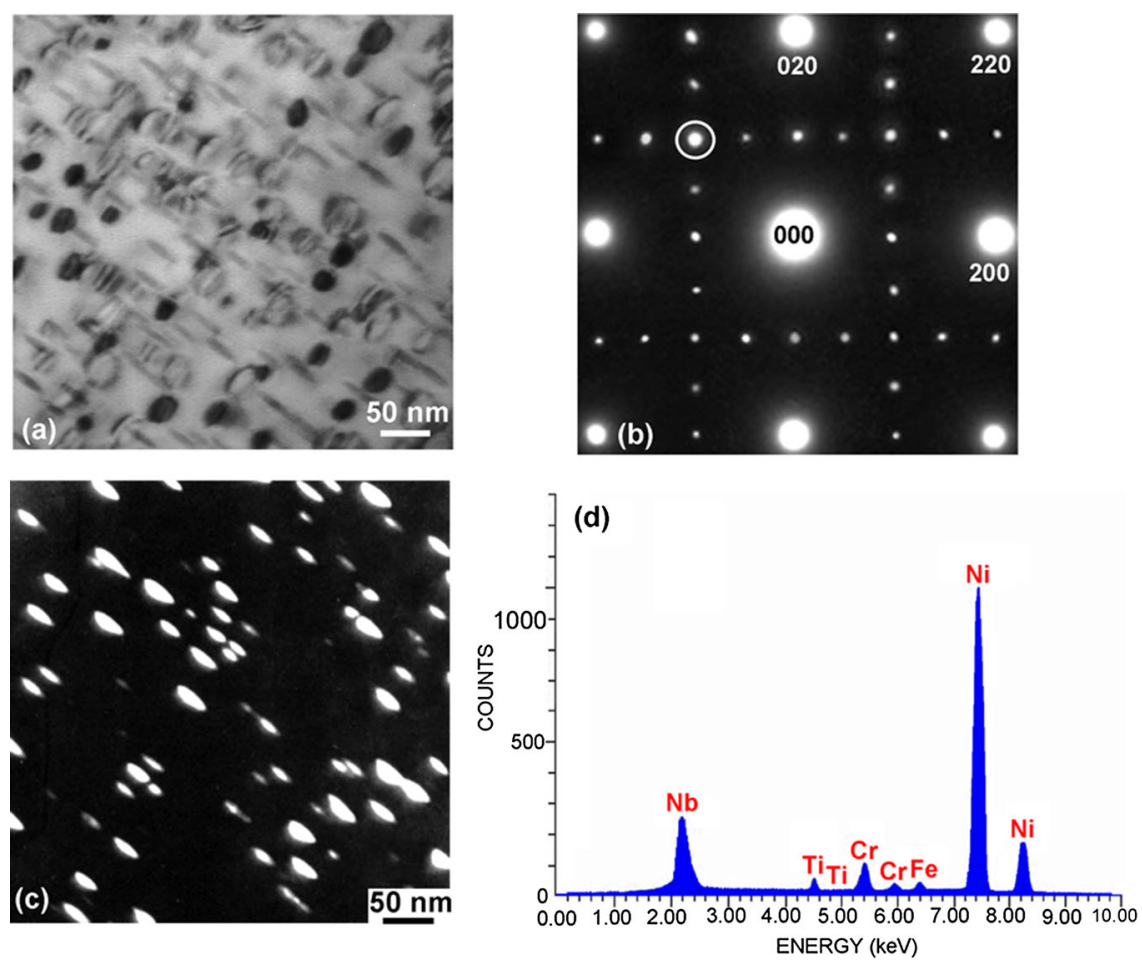
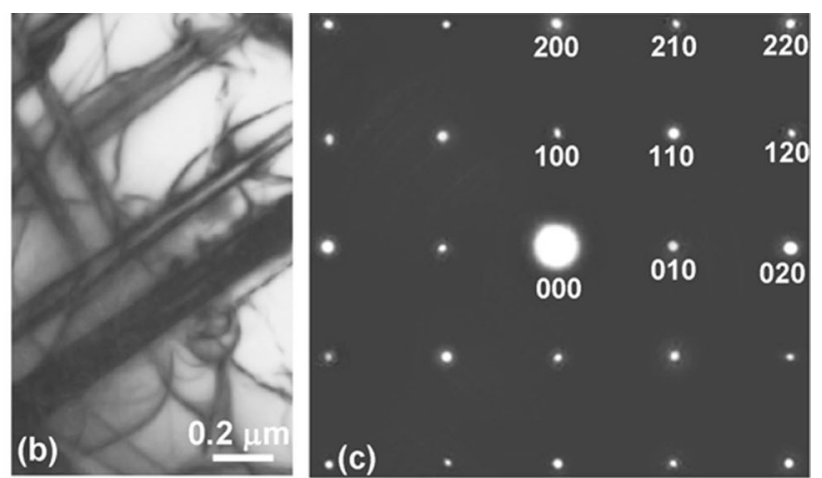

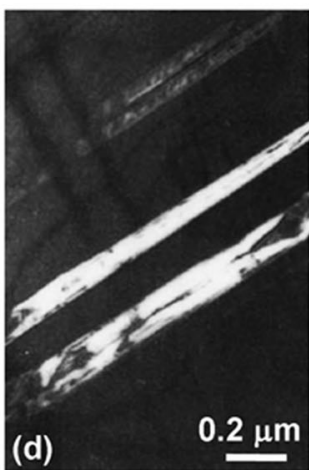

Fig. 18 Microstructure of $\delta \mathrm{Ni}_{3} \mathrm{Nb}$ formed in alloy 625 after $4000 \mathrm{~h}$ of exposure at $760{ }^{\circ} \mathrm{C}$. (a) Secondary electron SEM image illustrating the platelet morphology of $\delta \mathrm{Ni}_{3} \mathrm{Nb}$. (b) Bright-field image showing the platelets of $\delta \mathrm{Ni}_{3} \mathrm{Nb}$ on the scale of TEM. (c) Microdiffraction

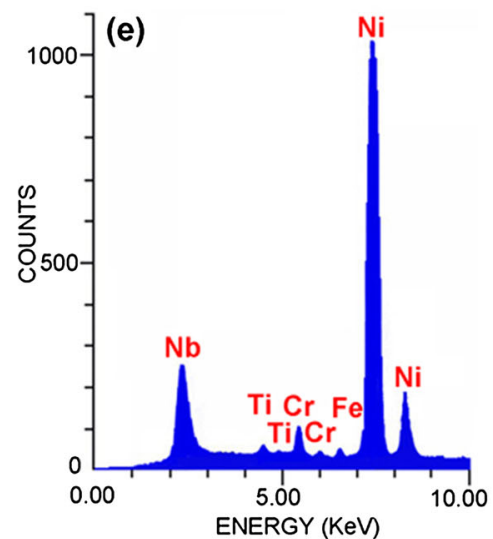

pattern consistent with the orthorhombic structure of $\delta \mathrm{Ni}_{3} \mathrm{Nb}$ in [001] orientation. (d) Corresponding dark-field TEM image formed with the (100) reflection in (c). (e) EDS spectrum illustrating the elemental composition of $\delta \mathrm{Ni}_{3} \mathrm{Nb}$ 
Fig. 19 Identification of Sistabilized Laves phase in alloy 625 after $24 \mathrm{~h}$ of aging at $760{ }^{\circ} \mathrm{C}$. (a) Bright-field TEM image showing an array of Laves phase particles at grain boundaries. (b) Microdiffraction pattern derived from the encircled particle in (a) and is consistent with the hexagonal structure of Laves phase in [120] orientation.

(c) Corresponding EDS spectrum illustrating the elemental composition of the particle

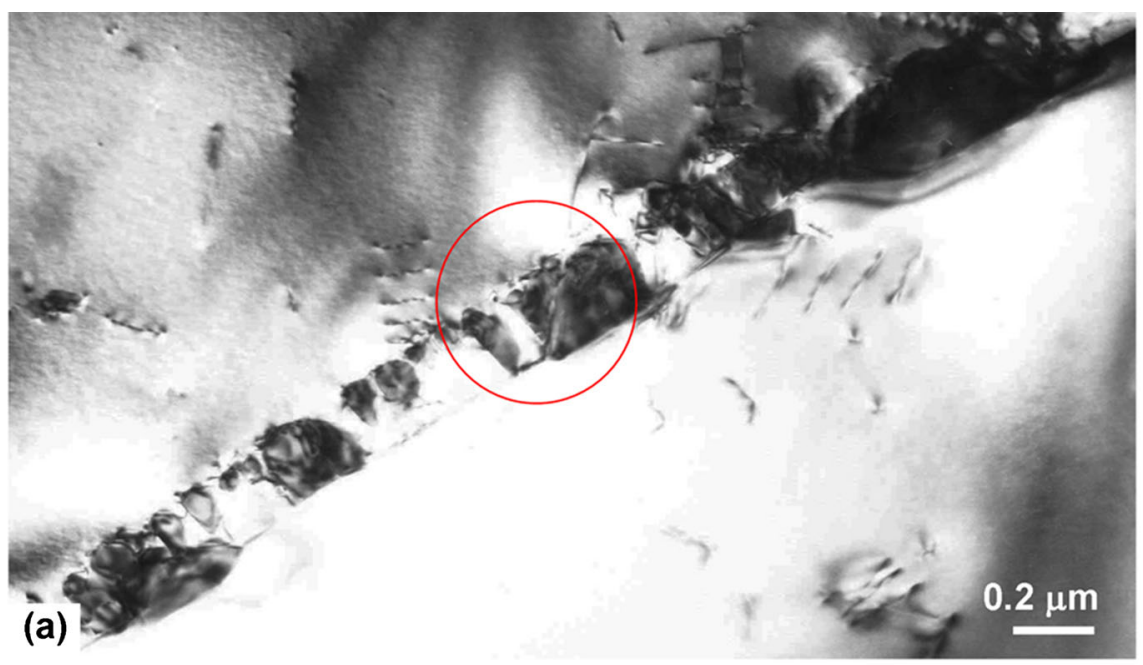

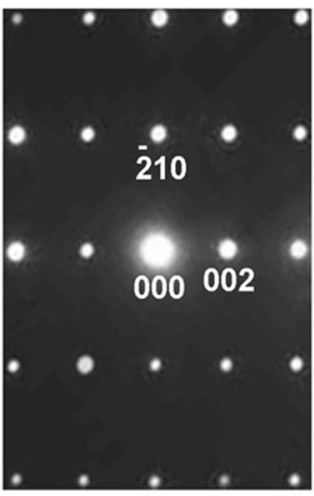

(b)

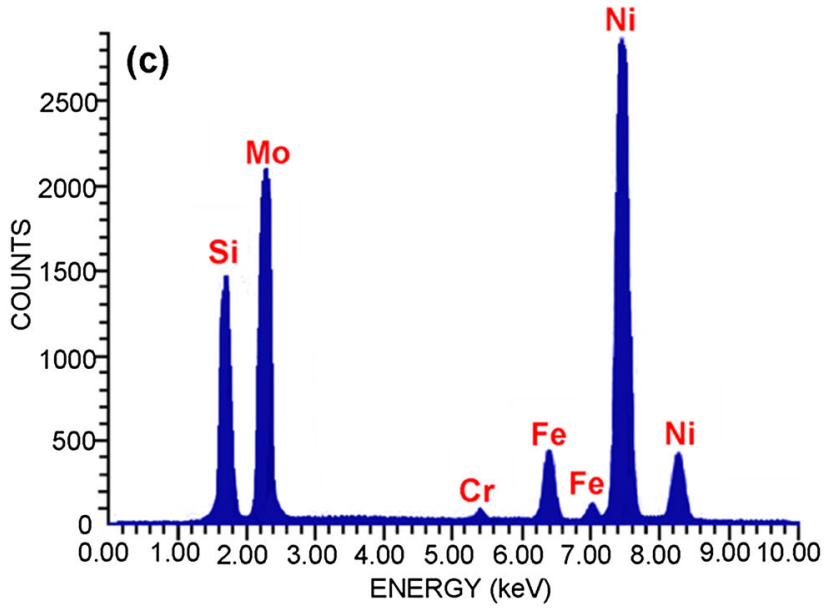

with the encircled (100) reflection is shown in Fig. 18d. The EDS spectrum of Fig. 18e illustrates the corresponding elemental composition, which is the same as that characterizing the $\gamma^{\prime \prime}$ phase (Fig. 17d). At temperatures higher than about $760{ }^{\circ} \mathrm{C}$ where the $\gamma^{\prime \prime}$ phase becomes thermodynamically unstable [28], the $\delta$ phase in platelet-type morphology is found to directly precipitate from the parent fcc structure [29, 30].

In addition to the $\mathrm{Ni}_{3} \mathrm{Nb}$ intermetallic, particles of Laves phase are observed to precipitate at grain boundaries during aging at $760{ }^{\circ} \mathrm{C}$. Figure 19 is an example showing the results of TEM/STEM analysis of Laves phase particles after $100 \mathrm{~h}$ of exposure. Figure 19a is a bright-field TEM image showing precipitate particles at a grain boundary. A microdiffraction pattern derived from the encircled particle in (a) is shown in Fig. $19 \mathrm{~b}$ and is consistent with the hexagonal structure of Laves phase $(a=0.48 \mathrm{~nm}$, $c=0.78 \mathrm{~nm})$ in [120] orientation. A corresponding EDS spectrum illustrating the elemental composition of the particle is shown in Fig. 19c indicating a Si-stabilized Laves phase of the type $\mathrm{Ni}_{3} \mathrm{Mo}_{2} \mathrm{Si}$ [8].

Figure 20 summarizes the effect of up to $16,000 \mathrm{~h}$ of exposure at 650,760 and $870{ }^{\circ} \mathrm{C}$ on the room temperature tensile properties. The changes in $0.2 \%$ yield strength (Fig. 20a) and tensile ductility (Fig. 20b) are most significant for aging at $650{ }^{\circ} \mathrm{C}$ followed by 760 and $870{ }^{\circ} \mathrm{C}$ in decreasing order. These differences are correlated with the relative density and morphology of the precipitates. Although the characteristic microstructure of $\gamma^{\prime \prime}$ phase still maintains a good combination of yield strength and tensile ductility, this is not the case for both the $\delta$ phase with platelet morphology and Laves phase, which have adverse effects on tensile ductility. In general, the densities of both intermetallics are observed to decrease with temperature, which can explain the observation of Fig. 20. Transformation of the $\gamma^{\prime \prime}$ phase into the $\delta$ phase is found to be most pronounced at $650{ }^{\circ} \mathrm{C}$ followed by $760{ }^{\circ} \mathrm{C}$ in decreasing order. However, at $870{ }^{\circ} \mathrm{C}$ where the $\gamma^{\prime \prime}$ phase becomes 


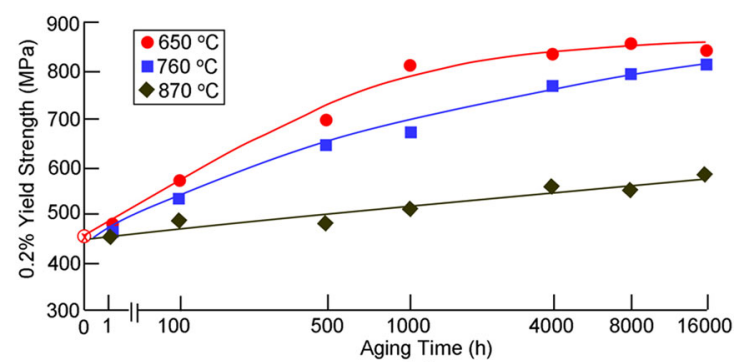

(a)

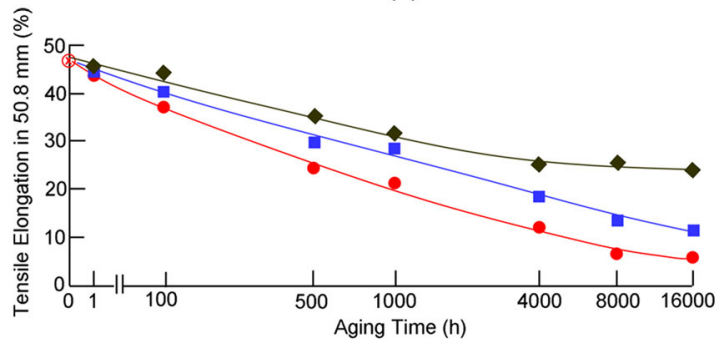

(b)

Fig. 20 Effect of up to $16,000 \mathrm{~h}$ of aging at different temperatures on the room temperature tensile properties of alloy 625 . (a) $0.2 \%$ yield strength. (b) Tensile elongation in $50.8 \mathrm{~mm}$ gage length

unstable, the $\delta$ phase is found to directly precipitate from the parent fcc structure as pointed out earlier. On the other hand, the tendency to precipitate Laves phase is found to diminish at higher aging temperatures.

\section{Conclusions}

The susceptibility of selected solid-solution-strengthened Ni-base alloys of commercial grade to precipitating intermetallic compounds during aging at high temperatures and the corresponding effects on mechanical properties have been correlated with the nature and concentration of alloying elements. An alloy with high concentrations of $\mathrm{Fe}$ and $\mathrm{Cr}$ such as alloy $\mathrm{X}$ is found to be most susceptible to precipitating the detrimental $\mathrm{FeCr}$ sigma phase. Small concentrations of $\mathrm{Fe}$ in alloys based on the Ni-Mo system such as alloy B are found to decelerate the kinetics of detrimental $\mathrm{Ni}_{3} \mathrm{Mo}$ and $\mathrm{Ni}_{4} \mathrm{Mo}$ compounds in contrast to the case of alloy B-2, which is relatively free of Fe. On the other hand, various concentrations of Fe combined with heavy transition metals such as $\mathrm{W}$ and Mo as well as smaller concentrations of cobalt are found to stabilize the detrimental $(\mathrm{Ni}, \mathrm{Co}, \mathrm{Fe})_{6}(\mathrm{~W}, \mathrm{Mo})_{7}$-type mu phase in alloys $\mathrm{X}$ and $\mathrm{C}-276$. On the other hand, alloys closely related to alloy C-276 such as alloys S and C-4 are highly stable toward precipitating mu phase, which has been correlated with the very small concentrations of $\mathrm{Fe}, \mathrm{Co}$ and $\mathrm{W}$. However, under certain aging conditions, alloys S, C-4 and C-276 are found to precipitate the $\mathrm{Ni}_{2}(\mathrm{Mo}, \mathrm{Cr})$ intermetallic, which produces a combination of high strength and high ductility. Also, the $\gamma^{\prime \prime}$ phase of $\mathrm{Ni}_{3} \mathrm{Nb}$ formed in alloy 625 is found to produce a combination of high strength and high ductility; however, considerable loss of ductility occurs when the $\gamma^{\prime \prime}$ phase is transformed into the $\delta$ phase of $\mathrm{Ni}_{3} \mathrm{Nb}$ due to change in precipitate morphology. On the other hand, the relatively high Si content of alloy 625 is found to stabilize the detrimental $\mathrm{Ni}_{3} \mathrm{Mo}_{2} \mathrm{Si}$ type Laves phase.

Acknowledgments The author is grateful for the continued support provided by King Fahd University of Petroleum and Minerals.

\section{References}

1. L.M. Pike, 100+ years of wrought alloy development at Haynes international, in 8th International Symposium on Superalloy 718 and Derivatives, ed. by E. Ott, A. Banik, X. Liu, I. Dempster, K. Heck, J. Anderson, J. Groh, T. Gabb, R. Helmink, A. Wusatowska-Sarnek (The Minerals, Metals and Materials Society, Warrendale, PA, 2014), p. 15

2. V.P. Deodeshmukh, S.K. Srivastava, The oxidation performance of modern high-temperature alloys. JOM 61, 56-59 (2007)

3. D.L. Klarstrom, H.M. Tawancy, M.F. Rothman, Structure/property relationships in solid-solution strengthened superalloys, in Superalloys, ed. by W.B. Ken, M. Gell (The Metallurgical Society of AIME, Warrendale, PA, 1984), p. 553

4. C.T. Sims, Prediction of phase composition, in Superalloys II, ed. by C.T. Sims, W.C. Hagel, N.S. Stoloff (Wiley, New York, 1987), p. 217

5. R.C. Reed, The Superalloys: Fundamentals and Applications (Cambridge University Press, Cambridge, 2006), p. 33

6. M.J. Donachie, S.J. Donachie, Superalloys: A Technical Guide, 2nd edn. (ASM International, Materials Park, OH, 2002), p. 25

7. H.M. Tawancy, Precipitation characteristics of mu-phase in wrought nickel-base alloys and its effect on their properties. J. Mater. Sci. 31, 3929-3936 (1996)

8. G. Wallwork, J. Croll, A review of the strengthening mechanisms in iron and nickel based $\mathrm{Fe}-\mathrm{Ni}-\mathrm{Cr}$ alloys used at high temperatures, in Reviews of High Temperature Materials, vol. 3 no. 2, ed. by J.B. Newkirk (Freund Publishing House, London, 1976), p. 69

9. H.M. Tawancy, M.O. Aboelfotoh, Mechanical properties of ground state structures in substitutional ordered alloys: high strength, high ductility and high thermal stability. Mater. Sci. Eng., A 603, 121-128 (2014)

10. H.M. Tawancy, L.M. Al-Hadhrami, A nanocrystalline $\mathrm{Ni}_{2}(\mathrm{Cr}$, Mo) intermetallic with potentially useful combination of properties for gas turbine seal ring applications. J. Mater. Eng. Perform. 21, 1374-1379 (2012)

11. H.M. Tawancy, Synthesis of bulk nanostructured $\mathrm{DO}_{22}$ superlattice of $\mathrm{Ni}_{3}(\mathrm{Mo}, \mathrm{Nb})$ with high strength, high ductility and high thermal stability. J. Nanomater. 2012, 387694 (2012)

12. H.M. Tawancy, Long-range ordering: an approach to synthesize nanoscale Ni-Mo-based superlattices with high strength and high ductility. Mater. Sci. Forum 653-654, 421-435 (2010)

13. H.M. Tawancy, M.O. Aboelfotoh, Application of long-range ordering in the synthesis of nanoscale $\mathrm{Ni}_{2}(\mathrm{Cr}, \mathrm{Mo})$ superlattice with high strength and high ductility. Mater. Sci. Eng., A 500, 188-195 (2009)

14. H.M. Tawancy, M.O. Aboelfotoh, High strength and high ductility in a nanoscale superlattice of $\mathrm{Ni}_{2}(\mathrm{Cr}, \mathrm{Mo})$ deformable by twinning. Scr. Mater. 59, 846-849 (2008) 
15. R. Darolia, D.F. Lahrman, R.D. Field, Formation of topologically close-packed phases in nickel base single crystal superalloys, in Superalloys, ed. by S. Reichman, D.N. Duhl, G. Maurer, S. Antolovich, C. Lund (The Metallurgical Society, Warrendale, PA, 1988), p. 255

16. E.R. Ross, C.T. Sims, Nickel-base alloys, in Superalloys II, ed. by C.T. Sims, N.S. Stoloff, W.C. Hagel (Wiley, New York, 1987), p. 97

17. H.M. Tawancy, Failure analysis of process equipment used in the production of polyvinyl chloride. Metallogr. Microstruct. Anal. 3, 310-322 (2014)

18. J.B. Mitchell, Imperfection and microstructure. Metallography $\mathbf{8}$, 5-70 (1975)

19. F.R. Beckitt, B.R. Clark, The shape and mechanism of formation of $\mathrm{M}_{23} \mathrm{C}_{6}$ carbide in austenite. Acta Metall. 15, 113-129 (1967)

20. M.H. Lewis, B. Hattersley, Precipitation of M23C6 in austenitic steels. Acta Metall. 13, 1159-1168 (1965)

21. J.W. Edington, Typical Electron Microscope Investigations (N.V. Philips, Eindhoven, 1976), p. 38

22. X.Z. Qin, J.T. Guo, C. Yuan, G.X. Yang, L.Z. Zhou, H.Q. Ye, $\mu-$ Phase behavior in a cast Ni-base superalloy. J. Mater. Sci. 44, 4840-4847 (2009)

23. H.M. Tawancy, Precipitation characteristics of mu-phase in wrought nickel-base alloys and its effect on their properties. J. Mater. Sci. 31, 3929-3936 (1996)
24. C.R. Brooks, J.E. Spruiell, E.E. Stansbury, Physical metallurgy nickel-molybdenum alloys. Int. Metals Rev. 29, 210-248 (1984)

25. H.M. Tawancy, Long-range ordering behavior and mechanical properties of Ni-Mo alloys. J. Mater. Sci. 30, 522-537 (1995)

26. S. Floreen, G.E. Fuchs, W.J. Yang, The metallurgy of alloy 625 , in Superalloys 718, 625, 706 and Various Derivatives, ed. by E.A. Loria (The Minerals, Metals and Materials Society, Warrendale, PA, 1994), p. 13

27. G. Thomas, Precipitation hardened alloys, in Electron Microscopy and Strength of Crystals, ed. by G. Thomas, J. Washburn (Wiley Interscience, New York, 1963), p. 793

28. P.M. Mignanelli, N.G. Jones, K.M. Perkins, M.C. Hardy, H.J. Stone, Microstructural evolution of delta containing nickel-base superalloy during heat treatment and isothermal forging. Mater. Sci. Eng., A 621, 265-271 (2015)

29. M. Sundararaman, P. Mukhopadhyay, S. Banerjee, Precipitation of the $\delta \mathrm{Ni}_{3} \mathrm{Nb}$ phase in two nickel base superalloys. Metall. Mater. Trans. 19A, 453-465 (1988)

30. L.M. Suave, D. Bertheau, J. Cormier, P. Villechaise, A. Soula, Z. Hervier, F. Hamon, J. Laigo, Impact of thermomechanical aging on alloy 625 high temperature mechanical properties, in 8th International Symposium on Superalloy 718 and Derivatives, ed. by E. Ott, A. Banik, X. Liu, I. Dempster, K. Heck, J. Anderson, J. Groh, T. Gabb, R. Helmink, A. Wusatowska-Sarnek (The Minerals, Metals and Materials Society, Warrendale, PA, 2014), p. 317 